\title{
SILICA MEMBRANES FOR HYDROGEN SEPARATION \\ IN COAL GAS PROCESSING
}

FINAL REPORT, JANUARY 1993

\section{G. R. Gavalas}

Work Performed Under Grant No. DE-FG22-89PC89765

For

U.S. Department of Energy

Pittsburgh Energy Technology Center

Pittsburgh, PA 15236

By

California Institute of Technology

Pasadena, CA 91125

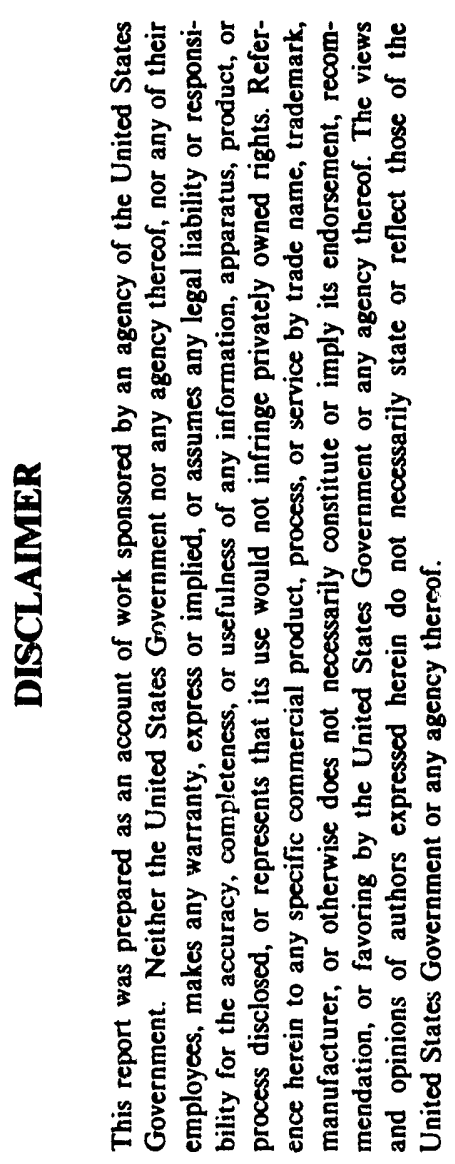

MASIEA 
SUMMARY 1

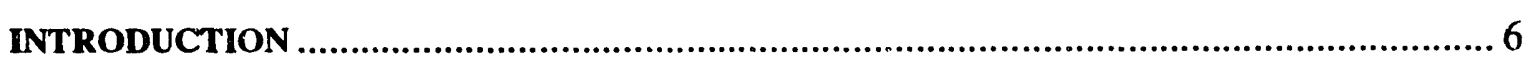

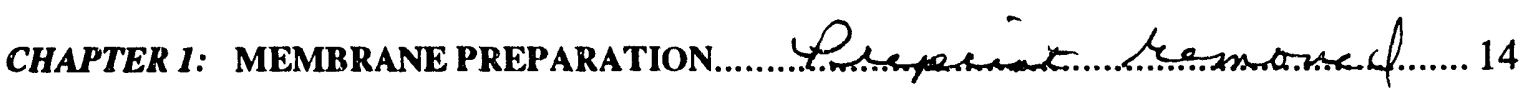

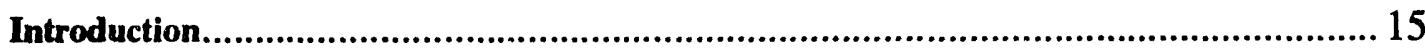

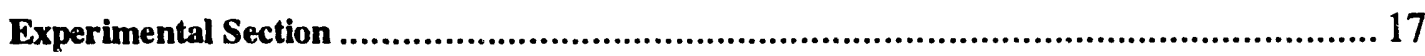

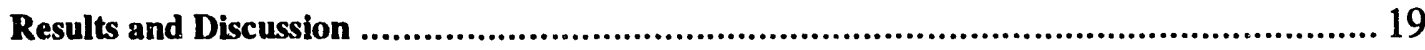

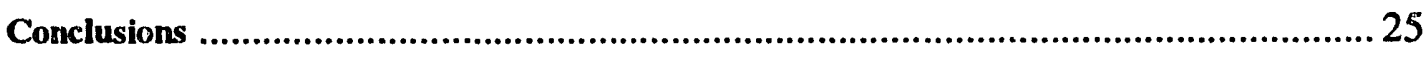

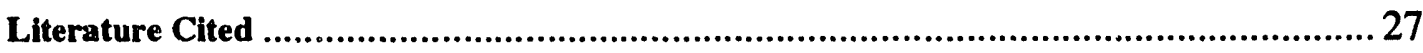

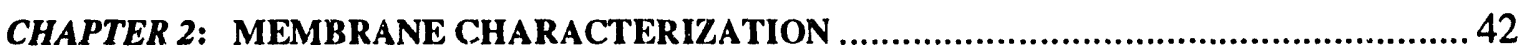

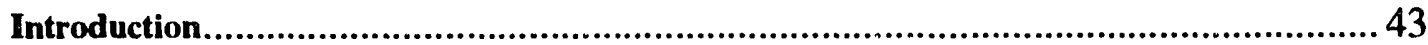

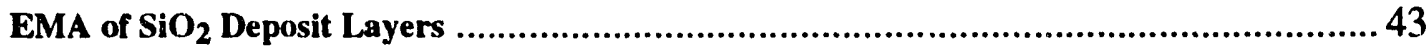

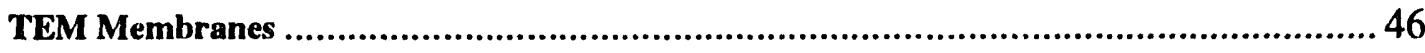

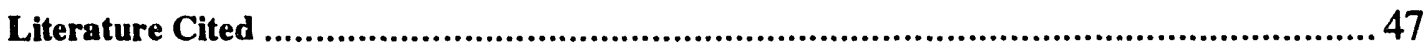

CHAPTER 3: THERMOGRAVIMETRIC ANALYSIS OF THE REACTIONS OF $\mathrm{SICl}_{4}, \mathrm{TICl}_{4}$ AND $\mathrm{H}_{2} \mathrm{O}$ WITH THE VYCOR SURFACE ............................52

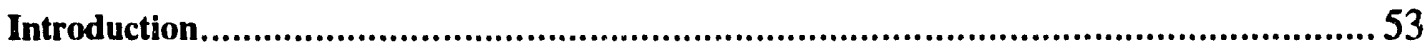

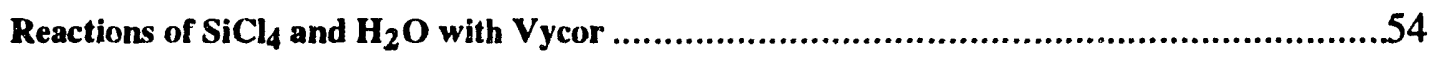

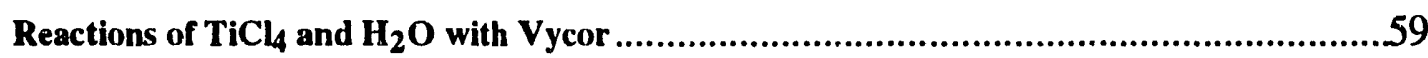

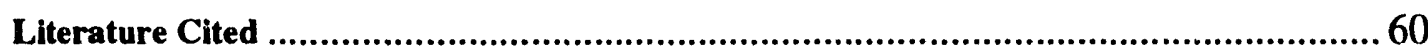

CHAPTER 4: MODEL OF MEMBRANE FORMATION BY CVD OF $\mathrm{SiO}_{2}$ AND $\mathrm{Al}_{2} \mathrm{O}_{3} \ldots \ldots \ldots . .91$

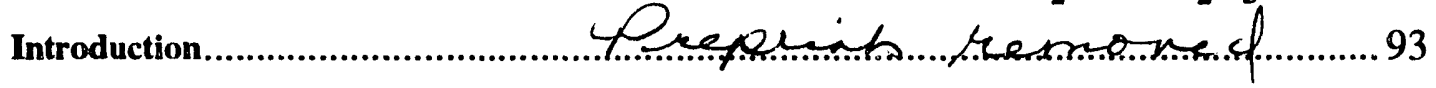

Experimental Apparatus and Procedure ........................................................... 95

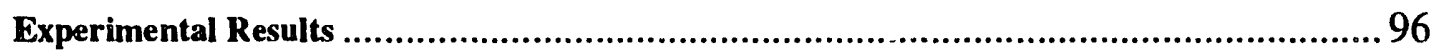

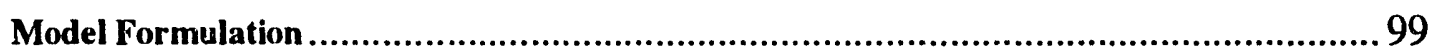

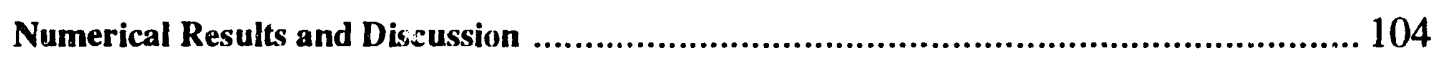

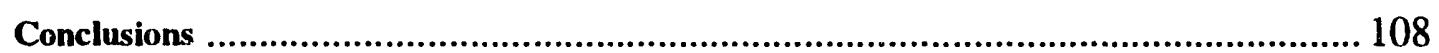

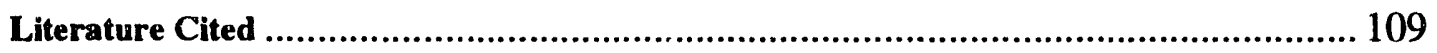

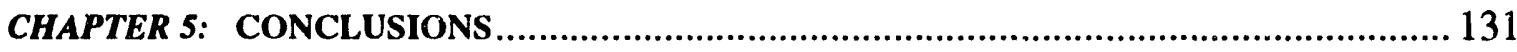




\section{SUMMARY}

The general objective of this project was to synthesize permselective membranes suitable for hydrogen separation from coal gas. The specific objectives were: (i) to synthesize membranes by chemical vapor deposition (CVD) of $\mathrm{SiO}_{2}$ or other oxides on porous support tubes, (ii) characterize the membranes by permeation measurements of various gases and by electron microscopy, and (iii) obtain information about the mechanism and kinetics of $\mathrm{SiO}_{2}$ deposition, and model the process of membrane formation.

\section{Membrane Preparation}

Silica glass and certain other glasses, in dense (nonporous) form, are highly selective to hydrogen permeation. Since this high selectivity is accompanied by low permeability, however, a practical membrane must have a composite structure sonsisting of a thin layer of the active oxide supported on a porous tube or plate p: oviding mechanical support. In this project the membranes were synthesized by chemical vapor deposition (CVD) of $\mathrm{SiO}_{2}, \mathrm{TiO}_{2}, \mathrm{Al}_{2} \mathrm{O}_{3}$ and $\mathrm{B}_{2} \mathrm{O}_{3}$ layers inside the walls of porous Vycor tubes ( $5 \mathrm{~mm} \mathrm{ID}, 7 \mathrm{~mm}$ OD, $40 \AA$ mean pore diameter).

Deposition of the oxide layer was carried out using the reaction of $\mathrm{SiCl}_{4}$ (or $\mathrm{TiCl}_{4}, \mathrm{AlCl}_{3}, \mathrm{BCl}_{3}$ ) and water vapor at elevated temperatures. The porous support tube was inserted concentrically into a larger quartz tube and fitted with flow lines and pressure gauges. The flow of the two reactant streams was regulated by mass flow controllers, while the temperature was controlled by placing the reactor into a split-tube electric furnace.

The deposition was carried out either in the "opposed reactants geometry" or in the "one-sided geometry". In the former, one of the reactant streams $\left(\mathrm{SiCl}_{4}-\mathrm{H}_{2}\right)$ was passed through the bore of the porous tube while the second reactant stream $\left(\mathrm{H}_{2} \mathrm{O}-\mathrm{N}_{2}\right)$ 
was passed through the annulus between the porous tube and the surrounding quartz tube. In the one-sided geometry both reactants as a single stream, $\mathrm{SiCl}_{4}-\mathrm{H}_{2} \mathrm{O}-\mathrm{N}_{2}$, were passed through the bore of the support tube or through the annulus. During reaction the pores of the support tube were gradually constricted by the deposition of the oxide resulting in gradual reduction of gas permeation rates. This reduction is minor for hydrogen permeation, for the thin layer of deposited $\mathrm{SiO}_{2}$ offers little resistance to diffusion. However, for other gases the reduction is very pronounced. For $\mathrm{N}_{2}$, for example, the permeance decreases by a factor of as much as 1000 . This disproportionately sharp permeance reduction for gases other than hydrogen (and $\mathrm{He}$ ) is the basis of the hydrogen permselectivity of the $\mathrm{SiO}_{2}$ membranes.

To follow the progress of pore constriction and determine the proper time for terminating the reaction, the flow of reactants was interrupted every few minutes to measure, in situ, the membrane permeance to nitrogen, hydrogen and occasionally other gases.

During the first year of the project, deposition of $\mathrm{SiO}_{2}$ was carried out in the opposing reactants geometry at atmospheric pressure and temperature $700-800^{\circ} \mathrm{C}$. The two reactant streams were $30 \% \mathrm{SiCl}_{4}-\mathrm{N}_{2}$ and $7 \% \mathrm{H}_{2} \mathrm{O}-\mathrm{N}_{2}$. The membranes prepared under these conditions had hydrogen permeance at $450^{\circ} \mathrm{C}$ of $0.1 \mathrm{~cm}^{3}(\mathrm{STP}) / \mathrm{cm}^{2}$-min-atm and $\mathrm{H}_{2}: \mathrm{N}_{2}$ permeation ratio $1000-5000$.

We later found out that deposition in the one-sided geometry required less time and yielded membranes of higher permeance, about $0.3 \mathrm{~cm}^{3}(\mathrm{STP}) / \mathrm{cm}^{2}$-min-atm at $450^{\circ} \mathrm{C}$ with $\mathrm{H}_{2}: \mathrm{N}_{2}$ permeance ratio in the range 1000-2000. Much of the later membrane preparation work was, therefore, carried out by one sided deposition.

The stability of the $\mathrm{SiO}_{2}$ membrane was tested by heating them for several hours at $700-750^{\circ} \mathrm{C}$ in dry nitrogen, as a result of which they underwent slight decline in hydrogen permeance $(\sim 10 \%)$ and moderate improvement in the $\mathrm{H}_{2}: \mathrm{N}_{2}$ selectivity. When the membranes were heated for extended periods (several days) in the presence of water 
vapor, they underwent sharp decline of hydrogen permeance without appreciable change of permselectivity. For example, in two weeks heating at $550^{\circ} \mathrm{C}$ at $3 \mathrm{~atm}$ partial pressure of $\mathrm{H}_{2} \mathrm{O}$ the hydrogen permeance at $500^{\circ} \mathrm{C}$ declined by a factor of 3 to a seemingly stable value of $0.1 \mathrm{~cm}^{3} / \mathrm{cm}^{2}$-min-atm. This decline is associated with an increase of the activation energy from about $16 \mathrm{~kJ}$ mol for the as-prepared membranes to $32 \mathrm{~kJ}$ for the membrane's after hydrothermal treatment.

One of the objectives of this project was to investigate the permeation properties of several oxides other than $\mathrm{SiO}_{2}$, namely $\mathrm{TiO}_{2}, \mathrm{Al}_{2} \mathrm{O}_{3}$ and $\mathrm{B}_{2} \mathrm{O}_{3}$. A number of $\mathrm{TiO}_{2}$ and $\mathrm{Al}_{2} \mathrm{O}_{3}$ membranes were prepared in the opposing reactants geometry by the reaction of water vapor with $\mathrm{TiCl}_{4}$ and $\mathrm{AlCl}_{3}$, respectively. The hydrogen permeance of the $\mathrm{TiO}_{2}$ membranes was slightly lower and the $\mathrm{H}_{2}: \mathrm{N}_{2}$ selectivity significantly lower than those of the $\mathrm{SiO}_{2}$ membranes prepared in the opposing reactant geometry. The $\mathrm{Al}_{2} \mathrm{O}_{3}$ membranes had permeance and selectivity lower than those of the $\mathrm{TiO}_{2}$ membranes. In contrast to the $\mathrm{SiO}_{2}$ membranes that could be prepared in both the opposing reactants and the onesided geometry, the $\mathrm{TiO}_{2}$ and $\mathrm{Al}_{2} \mathrm{O}_{3}$ membranes could be prepared only in the opposing reactants geometry.

Boron oxide membranes could be prepared in the one-sided as well as in the opposing reactants geometry over a wide range of temperatures. Membranes prepared in the opposing reactants geometry had similar hydrogen permeance and $\mathrm{H}_{2}: \mathrm{N}_{2}$ selectivities with those of the $\mathrm{SiO}_{2}$ membranes. However, upon exposure to humid laboratory air for extended periods, the $\mathrm{B}_{2} \mathrm{O}_{3}$ membranes developed microcracks and lost their selectivity.

\section{Membrane Characterization}

Scanning electron microscopy (SEM), electron microprobe analysis (EMA), and transmission electron microscopy (TEM) were employed to determine the physical structure of the membranes. SEM of polished tube cross section provided information about the spatial extent and gross texture of the deposit layer. For $\mathrm{Al}_{2} \mathrm{O}_{3}$ and $\mathrm{TiO}_{2}$ 
membranes prepared in the opposing reactants geometry the deposit layer occupied a region extending from the bore surface of the tube (which was the side of the chloride flow) to about $50 \mu \mathrm{m}$ depth. The deposit layer appeared nonuniform having maximum density at the end away from the tube bore (in the interior of the tube wall). Similar spatial distribution was observed for the $\mathrm{SiO}_{2}$ membranes prepared in the opposing reactants geometry. In the $\mathrm{SiO}_{2}$ membrane layers prepared in the one-sided geometry, the deposit layer was thinner, 10-20 $\mu \mathrm{m}$, and the maximum density, as expected, was observed right at the bore surface (the side of the reactants). Occasionally the deposit layer extended slightly outside of the tube wall towards the bore (lumen) of the tube.

More quantitative information about the spatial (radial) density profile of the deposit was obtained from EMA scans of polished cross sections of membrane tubes. $\mathrm{TiO}_{2}, \mathrm{Al}_{2} \mathrm{O}_{3}$ and $\mathrm{SiO}_{2}$ deposit layers prepared by opposing reactants deposition had an asymmetric density profile. Confirming the SEM results the deposit layer was found to consist of a slowly rising part followed by a sharp peak steeply dropping to zero.

TEM was used to determine the nanostructure of the region at the peak of the deposit layer. Ion milling and ultramicrotomy were used to prepare samples of suitable thickness. The peak region was found to have thickness about $0.5 \mu \mathrm{m}$ and to contain some residual (trapped) porosity.

\section{Kinetic Experiments and Kinetic Modeling}

The mechanism and kinetics of $\mathrm{SiO}_{2}$ deposition by the reaction between $\mathrm{SiCl}_{4}$ and $\mathrm{H}_{2} \mathrm{O}$ were investigated using a thermogravimetric analysis system (TGA). Deposition proceeds by a heterogeneous mechanism which may be summarized by the following reaction network:

$$
\begin{gathered}
\mathrm{Si}-\mathrm{OH}(\mathrm{s})+\mathrm{SiCl}_{4}(\mathrm{~g})=3 \mathrm{Si}-\mathrm{Cl}(\mathrm{s})+\mathrm{HCl}(\mathrm{g}) \\
\left.\mathrm{Si}-\mathrm{Cl}(\mathrm{s})+\mathrm{H}_{2} \mathrm{Og}\right)=\mathrm{Si}-\mathrm{OH}(\mathrm{s})+\mathrm{HCl}(\mathrm{g})
\end{gathered}
$$




$$
\begin{aligned}
\mathrm{Si}-\mathrm{OH}(\mathrm{s})+\mathrm{Si}-\mathrm{OH}(\mathrm{s}) & =\mathrm{Si}-\mathrm{O}-\mathrm{Si}(\mathrm{s})+\mathrm{H}_{2} \mathrm{O}(\mathrm{g}) \\
\mathrm{Si}-\mathrm{OH}(\mathrm{s})+\mathrm{Si}-\mathrm{Cl}(\mathrm{s}) & =\mathrm{Si}-\mathrm{O}-\mathrm{Si}(\mathrm{s})+\mathrm{HCl}(\mathrm{g})
\end{aligned}
$$

where $\mathrm{Si}-\mathrm{OH}(\mathrm{s}), \mathrm{Si}-\mathrm{Cl}(\mathrm{s}), \mathrm{Si}-\mathrm{O}-\mathrm{Si}(\mathrm{s})$ denote a hydroxyl (silanol), chloride, or siloxane bridge inside or on the surface of the deposit layer.

In the TGA experiments the reactions were decoupled by alternatingly reaction with $\mathrm{SiCl}_{4}$ and reaction with $\mathrm{H}_{2} \mathrm{O}$ with inert purge after each reaction period. Additional information was obtained by reaction with $\mathrm{Si}\left(\mathrm{CH}_{3}\right)_{3} \mathrm{Cl}$ (trimethylchlorosilane). Experiments were carried out at $400,450,500$ and $600^{\circ} \mathrm{C}$. Additional kinetic experiments using the TGA were performed for the reactions of $\mathrm{TiCl}_{4}$ and $\mathrm{H}_{2} \mathrm{O}$ producing $\mathrm{TiO}_{2}$.

\section{Model of Membrane Formation}

Membrane formation involves reaction, diffusion, and accompanying gradual constriction of the pores. To obtain high membrane permeance the deposit layers must be as thin as possible, hence, the reaction must take place under strong diffusional limitations, i.e. at high Thiele modulus. Because of the transient nature of the process the reaction never achieves a pseudosteady state, as in catalytic reactions. Full transient kinetics, taking into account the concentrations of silanol and chloride groups in the deposit layer must, therefore, be considered. Considerable effort was expended to develop a model describing transient kinetics, diffusion and simultaneous evolution of the pore structure. The model was formulated in terms of a set of nonlinear partial differential equations. Numerical solution of these equations provided deposit density profiles in qualitative agreement with the profiles measured with EMA. This agreement broke down a little before the percolation threshold was reached. 


\section{INTRODUCTION}

Among various technologies involved in coal utilization, bulk gas separation is one of the most important in terms of overall thermal efficiency and economics. Oxygen separation from air is a large energy user in oxygen-blown gasification processes. Hydrogen separation form coal gas is a large part of coal utilization processes producing chemicals like ammonia or liquid fuels. Separation and recycle of hydrogen from molten carbonate or solid oxide fuel cells can improve the efficiency of these advanced processes for electrical power from coal. For large scale oxygen separation air liquefaction is probably still the most efficient process, although separation by polymer membranes has been gaining ground in smaller scale applications. Hydrogen separation from mixtures containing $\mathrm{CO}, \mathrm{CO}_{2}, \mathrm{~N}_{2}$, etc. can be carried out by pressure swing adsorption (PSA) in molecular sieve beds, or by polymeric membranes, both of which are used commercially.

In processes involving hydrogen production from coal gas, membrane separation is more efficient than the alternative PSA if it could be integrated with the catalytic water gas shift reaction. Carrying out hydrogen separation in parallel with the reaction can increase significantly the equilibrium-limited yield. For this purpose the membrane must be capable of operating at the reaction temperature. Likewise, recovery and recycle of hydrogen in molten carbonate fuel cells would also be more efficient if conducted at the fuel cell temperature. Such separations can only be carried out using inorganic membranes which also offer the possibility of high selectivities, well above those of polymer membranes. High selectivity is necessary in the production of high purity hydrogen for ammonia or other chemical synthesis. For other applications like coal liquefaction having lower purity requirements, the hydrogen separation could be carried out by less selective inorganic membranes.

Inorganic membranes can be classified on the basis of their pore size into mesoporous (2-50 $\mathrm{nm}$ pore diameter) governed by Knudsen diffusion and nonporous or molecular sieve membranes wherein diffusion is activated and can be quite selective. 
Mesoporous Vycor glass tubes (mean pore size about $50 \AA$ ) were studied as gas separation membranes ${ }^{1-3}$ and also as membrane reactors for the conversion of $\mathrm{H}_{2} \mathrm{~S}$ to elemental sulfur ${ }^{4}$ and the dehydrogenation of cyclohexane. 5 These mesoporous Vycor membranes have Knudsen selectivity and relatively low permeance, since the selective separation layer occupies the entire tube wall. More recently alumina membranes have been prepared consisting of one or more coatings of decreasing pore size supported on macroporous (1-10 $\mu \mathrm{m}$ pore diameter) $\alpha-\mathrm{Al}_{2} \mathrm{O}_{3}$ tubes. The last layer in these membranes consists of mesoporous $\gamma-\mathrm{Al}_{2} \mathrm{O}_{3}$ deposited using sol gel techniques.6-11 These membranes are used commercially for ultrafiltration of liquids but have also been investigated in membrane-reactor applications, e.g. the dehydrogenation of ethane to ethylene. 12 Although their selectivity is low, governed by Knudsen diffusion, their permeance is high, since the final mesoporous layer is only a few microns thick.

Palladium and its alloys, especially with silver, are known to have essentially infinite selectivity and relatively high permeability for hydrogen at elevated temperatures. The permeation mechanism involves diffusion of atomic hydrogen through a metal hydride phase. Palladium alloy membranes have found limited laboratory applications and have been investigated extensively relative to improving the yield and selectivity of dehydrogenation reactions (see for example reference 13). The high cost and the susceptibility of palladium to embrittlement are obstacles to large scale applications. Certain base metals also form hydrides and are selectively permeable to hydrogen. Composite membranes are currently developed consisting of a vanadium layer sandwiched between intermediate layers of $\mathrm{SiO}_{2}$ and external layers of $\mathrm{Pt}$ or another noble metal. 14 The role of the noble metal is to catalyze the dissociation of molecular hydrogen, while the $\mathrm{SiO}_{2}$ layer is used to prevent interdiffusion between the noble metal and vanadium. These membranes are considered for possible application to the water gas shift reaction and the decomposition of hydrogen sulfide. 
Dense silica glass (and some other glasses) is also known to be highly selective towards permeation by light gases in the order helium, hydrogen, and neon. 15 Oxygen and other common gases have much lower permeability. At $500^{\circ} \mathrm{C}$, for example, the permeability of oxygen through Vycor glass (Corning code 7900) is four orders of magnitude lower than that of hydrogen. Nitrogen has even lower permeability. Sometime ago it was proposed to exploit the high helium permeability of Vycor to separate this gas from natural gas. But the main stimulus for studying the permeability properties of Vycor and other silica glasses has been in connection to the leak rate of various gases through high vacuum systems, light bulbs, and vacuum tubes. 16 The solubility and diffusivity of various gases through glass were reviewed by Shelby. ${ }^{i}$ In the case of hydrogen, it is generally accepted that the gas dissolves and diffuses through glass in molecular form, although a small contribution to the transport may involve reaction with siloxane bonds or exchange with silanols in the bulk of the glass. The high selectivity towards hydrogen permeation is due to the smaller molecular diameter of this gas (e.g. Lennard Jones diameters of $\mathrm{H}_{2}, \mathrm{O}_{2}, \mathrm{~N}_{2}$ are $2.91,3.43,3.68 \AA$ ). The amorphous silica network can accommodate hydrogen at numerous interstitial sites. Movement from site to site is activated $(32-40 \mathrm{~kJ} / \mathrm{mol})$, however, and diffusivity and permeability are low on an absolute basis. The permeability of hydrogen is sensitive to the glass composition and decreases by the presence of alkali or alkaline earth cations in the glass.

Although there is considerable difference among the glass permeabilities to various gases (e.g. $\mathrm{N}_{2}-\mathrm{O}_{2}$ ), the separation of gas mixtures other than those containing hydrogen is impractical because the permeabilities are extremely low. The only practical separation with glass membranes is that of hydrogen (or helium) from other gases. Even this separation, however, is practical only at elevated temperatures (because of the activation energy of diffusion). To obtain a reasonable permeance it is, moreover, necessary to employ a very thin silica layer supported by a thicker and highly permeable (porous) layer. This composite structure would provide high selectivity, high permeance, 
and mechanical strength in much the same way as in polymeric membranes. Although both planar and cylindrical (tubular) geometries can be used in the laboratory, only the tubular geometry is practical for large scale applications. The spiral geometry is clearly impractical for glass or other ceramic membranes.

Preparation of thin and dense (nonporous) glass layers on porous support tubes can be carried out by liquid phase or gas phase techniques. When liquid phase techniques are employed (e.g. sol-gel) the resulting silica layers are porous, the pores being generated during solvent evaporation or during the removal of gaseous products in subsequent calcination. Gas phase techniques (e.g. chemical vapor deposition) offer the possibility of depositing nonporous glass layers, for there is no solvent, and the products are removed during the main reaction. In this case drying and calcination are unnecessary.

A few years ago we became interested in the preparation of hydrogen membranes by chemical vapor deposition (CVD) of silica on mesoporous Vycor tubes as the support. Initially we used silane $\left(\mathrm{SiH}_{4}\right)$ oxidation for that purpose since this reaction is well known as a means of growing thin silica films. At the beginning we used one-sided deposition (both reactants passing from the same side of the support element) at low pressures as in the conventional CVD used for optical and electronic devices. The silica layers produced under these conditions were porous, unsuitable for selective separation. We then tried a different deposition arrangement where the two reactants $\left(\mathrm{SiH}_{4}\right.$ and $\left.\mathrm{O}_{2}\right)$ are passed from opposite sides of the tube wall-one through the bore and the other outside of the tube-both at atmospheric pressure. Under these flow conditions the reactants diffuse and react inside the porous wall of the support tube. With the accumulation of the solid product (silica) the pores become gradually constricted and eventually all open paths between the bore and the outside of the tube are blocked and reaction ceases. The resulting internal silica layer was nonporous and highly selective to 
hydrogen permeation. The results of membrane preparation using $\mathrm{SiH}_{4}$ oxidation have been reported previously. ${ }^{18-20}$

When employed in the opposing reactants geometry, silane oxidation is limited to a narrow temperature window around $450^{\circ} \mathrm{C}$. At temperatures lower than $400^{\circ} \mathrm{C}$ the reaction was too slow and the silica layer deposited too thick. Above $500^{\circ} \mathrm{C}$ rapid silane pyrolysis deposited elemental silicon throughout the porous wall. When the silica membranes produced at $450^{\circ} \mathrm{C}$ were heated in the presence of water vapor, they suffered a sharp decline of permeance and of ien a decline in selectivity as well. Somewhat better membrane properties were obtained by adding water vapor to the silane and oxygen reactants during deposition. The membranes produced in this fashion underwent significant decline of permeance but preserved their selectivity upon subsequent prolonged heating in the presence of water vapor.

Silica is produced commercially by the hydrolysis of silicon tetrachloride $\left(\mathrm{SiCl}_{4}\right)$ in an oxygen-hydrogen flame at temperatures above $900^{\circ} \mathrm{C}$. The high purity silica particles can be deposited and consolidated on a substrate forming a preform for the production of optical fibers. Gas phase hydrolysis of $\mathrm{SiCl}_{4}$ can also be carried out at lower temperatures but the mechanism and kinetics of this homogeneous hydrolysis are not known in detail. It is known, however, that high temperature flame hydrolysis is free radical in nature while the lower temperature (e.g. below $800^{\circ} \mathrm{C}$ ) hydrolysis proceeds by a nucleophilic mechanism. Much more is known about the reaction of $\mathrm{SiCl}_{4}$ and other chlorosilanes $\left(\left(\mathrm{CH}_{3}\right)_{3} \mathrm{SiCl},\left(\mathrm{CH}_{3}\right)_{2} \mathrm{SiCl}_{2}\right)$ and hydroxyl groups (silanols) with glass surfaces. These reactions have been of interest as a means of characterizing the concentration and type of surface hydroxyl groups. The reacuon of $\left(\mathrm{CH}_{3}\right)_{3} \mathrm{SiCl}$ and related compounds is used commercially or in the laboratory to render the surface of silica particles hydrophobic (for chromatography applications) or to make the surface of silica fibers compatible with polymers for composite materials fabrication. When the surface of glass is exposed to $\mathrm{SiCl}_{4}$ and $\mathrm{H}_{2} \mathrm{O}$ simultaneously, a stepwise formation of 
ilica takes place by the heterogeneous reaction network (1)-(4) shown in the Summary. This surface-initiated formation of $\mathrm{SiO}_{2}$ is particularly suitable for the deposition of thin silica layers on or within the wall of porous Vycor tubes. The heterogeneous reaction allows better control of the location and the structure of the deposit layer than is possible with the homogeneous reaction.

The general objective of this project was to investigate the fundamentals of membrane preparation by the hydrolysis of $\mathrm{SiCl}_{4}$. Specific issues to be investigated were the kinetics and mechanism of $\mathrm{SiO}_{2}$ deposition (reactions 1-4), characterization of the membrane layer; understanding the spatial structure of the membrane in terms of reaction, diffusion, and pore evclution, and developing techniques for preparation of thinner and more permeable membranes. Since $\mathrm{TiCl}_{4}, \mathrm{AlCl}_{3}, \mathrm{BCl}_{3}$ also react with water vapor or surface hydroxyl groups to form the respective oxides, an additional objective of this project was to prepare and examine the permeation properties of $\mathrm{TiO}_{2}, \mathrm{Al}_{2} \mathrm{O}_{3}$, and $\mathrm{B}_{2} \mathrm{O}_{3}$ layers.

This report is organized in five chapters. Chapter 1 describes membrane preparation. Chapter 2 describes characterization by electron microscopy. Chapter 3 describes the kinetics experiments. Chapter 4 describes the mathematical modeling work. The final Chapter 5 contains the general conclusions. 


\section{Literature Cited}

1. Shindo, Y., Hakuta, T., Yoshitome, H. and Inoue, H., Chem. Engng. Japan 17, 650 (1984).

2. Shindo, Y., Hakuta, T., Yoshitome, H. and Inoue, H., J. Chem. Engng. Japan 18, 485 (1985).

3. Haraya, K., Shindo, Y., Hakuda, T and Yoshitome, H., J. Chem. Engng. Japan 19, 186 (1986).

4. Kameyama, T., Dokiya, M., Fujishige, M., Yokokawa, H. and Fukuda, K. Ind. Engng. Chem. Fundam. 20, 97 (1981).

5. Sun, Y.-M and Khang, S.-J., I\&EC Research, 271136 (1988).

6. Leenaars, A. F. M. and Burggraaf, A. J., J. Colloid Interface Sci. 105, 27 (1978).

7. Keizer, K., Leenaars, A. F. M. and Burggraaf, A. J., in The Science of Ceramics, Vol. 12, Ceramurgica, Faenza, 1984.

8. Chu, P.-Y. and Clark, D. E., Aa'vanced Ceramic Materials 3, 249 (1988).

9. Okubo, T., Watanabe, M., Kusakabe, K. and Morrooka, S., J. Materials Sci. 25, 4822 (1990).

10. Okubo, T., Haruta, K., Kusakabe, K. and Morooka, S., J. Membrane Sci. 59, 73 (1991).

11. Cini, P., Blaha, S. R., Harold, M. P. and Venkataraman, K., J. Membrane Sci. 55, 199 (1991).

12. Champagnie, A. M., Tsotsis, T. T., Minet, R. G. and E. Wagner, J. Catal., 134, 713 (1992).

13. Gryaznov, V. M., Smirnov, V. S., and Slin'ko, M. G., Proc. Fifth International Congress Catalysis, The High Cost of Palladium, Vol. 2, North-Holland Publishing Co., Amsterdam, 1973, p. 1139. 
14. Edlund, D. J., abstract of a paper presented at the 12th annual gasification and gas stream cleanup systems contractors review meeting, Morgantown Energy Technology Center, September 15-17, 1992.

15. Boyd, D. C. and Thompson, D. A., "Glass" Encyclopedia of Chemicoll Technology 11, 807 (1980).

16. Leiby, Jr., C. C., and Chen, C. L., J. Chem. Phys. 31, 268 (1960).

17. Shelby, J. E., Molecular Solubility and Diffusion, in Treatise on Materials Science and T'echnology, Tomozawa, M. and Doremus, R. H. (Eds.), Vol. 17, Academic Press, 1979.

18. Gavalas, G. R., Megiris, C. E. and Nam, S. W., Chem. Eng. Sci. 441829 (1989).

19. Nam, S. W. and Gavalas, G. R., AIChE Symp. Ser. 85, 68 (1989).

20. Gavalas, G. R. and Megiris, C. E., U.S. Patent 4,902,307, 1990. 
Chapter 2

\section{MEMBRANE CHARACTERIZATION}

?

-

○ 


\subsection{Introduction}

Membrane characterization was carried out by scanning electron microscopy (SEM), electron microprobe analysis (EMA), and transmission electron microscopy (TEM). SEM was used to obtain information about the location and gross morphological features of the membranes. EMA was used to measure the spatial profile of the deposit density within the membrane layer. TEM was used to obtain smaller scale (nanoscale) features like the residual void fraction within the membrane layer.

During the early phases of the project SEM and EMA ware performed only for $\mathrm{TiO}_{2}$ and $\mathrm{Al}_{2} \mathrm{O}_{3}$ membranes. The results of this work have been included in Chapter 1 . SEM of silica layers did not provide useful information about the internal deposit layer, because both deposit and support consisted of the same material $\left(\mathrm{SiO}_{2}\right)$. However, SEM of the external surface of the support tube (the surface exposed to the reactants) in one-sided deposition revealed that when the flow of reactants is prolonged beyond pore plugging, deposition of small particles formed in the gas phase builds up an external layer which adversely affects the thermomechanical stability of the membrane. 1

Electron microprobe analysis of silica layers also encountered difficulties, due to the ablation of the deposit layer by the electron beam. By defocusing the electron beam, it was possible to overcome this difficulty, but at the cost of decreasing the spatial resolution. Section 2.2 below presents EMA scans of polished cross sections of silica membranes. SEM micrographs of the external surface of the support tubes have been presented in the final report of another project. 1

\subsection{EMA of $\mathrm{SiO}_{2}$ Deposit Layers}

EMA was carried out on polished tube cross sections using a JEOL 733 Superprobe electron microprobe by wavelength-dispersive spectroscopy. Sample preparation was carried out as discussed in the previous chapter. Figure 1 shows an EMA scan of a $\mathrm{SiO}_{2}$ layer prepared in the opposing reactants geometry during one hour 
deposition at $750^{\circ} \mathrm{C}$. Several features of this scan need to be discussed. First, the deposit layer is very thick, about $450 \mu \mathrm{m}$, occupying roughly one half of the tube wall, the side adjacent to the chloride flow. The layer is nonuniform, with the normalized deposit density increasing gradually from 0.025 (deposit density divided by support density) to 0.155 at the point of maximum density, and then abruptly dropping to zero. The spatial resolution provided by the defocused electron beam is low $(5-10 \mu \mathrm{m})$, therefore, each point in Figure 1 is an average of a 5-10 $\mu \mathrm{m}$ thick region. It is possible that the peak density located at around $415 \mu \mathrm{m}$ from the chloride side is actually considerably higher than 0.155 but is smeared by the measurement.

Continuing the discussion of the EMA scan of Figure 1 we note that in the largest part of the deposit layer the pores are only partially constricted and continue to accept Knudsen diffusion, albeit at a lower diffusion coefficient than in the untreated Vycor. In a thin sublayer, however, the percolation threshold has been exceeded and diffusion occurs through a dense phase or through ultramicropores. This sublayer is responsible for the selectivity of the membrane. Unfortunately, the thickness and the deposit density in this sublayer cannot be determined from the EMA scans because of the low spatial resolution. As expected from percolation theory, the pores within the sublayer are not completely filled, since when the percolation threshold is exceeded a certain trapped porosity remains. These issues are examined further in the subsection on TEM and in Chapter 4 dealing with the mathematical modeling of deposition.

One more point needs to be addressed in connection with Figure 1. In opposing reactants deposition, reaction stops when all open paths between the two sides of the support become blocked, this blocking obviously occurring in the sublayer of maximum density. Once this percolation threshold is exceeded the bulky $\mathrm{SiCl}_{4}$ molecules cannot diffuse through the sublayer. The smaller water molecules, however, continue diffusing slowly through the sublayer and reacting with $\mathrm{SiCl}_{4}$ in the region to the left of the sublayer causing a slow increase of the deposit density in that region. This slow 
thickening of the deposit layer improves somewhat the membrane selectivity but is detrimental to the permeance and, hence, is generally undesirable. The deposit layer shown in Figure 1 had probably experienced significant thickening due to the long duration of deposition.

Figure 2 shows the EMA scan of a membrane prepared by one-sided deposition. The thickness of the deposit layer is only about $20 \mu \mathrm{m}$ as compared to $450 \mu \mathrm{m}$ for the membrane of Figure 1. The shape of the deposit density profile is also different, having the peak density right at the bore surface (the sicie of reactants flow) as would be expected in one-sided deposition.

Although the deposit layer shown in Figure $Z$ is about $20 \mu \mathrm{m}$ thick, open pore paths are eliminated only in the much thinner sublayer at the boundary where the maximum deposit density is observed. This thin sublayer is responsible for the separation selectivity of the membrane while the bulk of the deposit layer reduces the permeance without contributing much to the selectivity. At the location of maximum deposit density, the $\mathrm{SiO}_{2}$ (deposit)/ $\mathrm{SiO}_{2}$ (support) mass ratio as measured by EMA is about 0.2 . Complete pore filling on the other hand would give a ratio of 0.4 , assuming that the deposit is as dense as Vycor. Similar differences were found for $\mathrm{SiO}_{2}, \mathrm{TiO}_{2}$, and $\mathrm{Al}_{2} \mathrm{O}_{3}$ membranes prepared by opposing reactants deposition. As discussed more extensively in Chapter 4, a major part of the difference between measured density and density estimated on the basis of complete pore filling should be attributed to the interruption of connectivity and the creation of trapped voids which are inaccessible to the reactants. These voids are trapped when surrounding pores narrower in diameter become plugged. In addition, small voids may be left behind within a single pore that becomes plugged due to nonuniform growth of $\mathrm{SiO}_{2}$ arising from the discrete nature of the initial growth sites (the silanol groups). Since EMA has very limited resolution, TEM was used to investigate the residual porosity within the deposit layer. 


\subsection{TEM of Membranes}

TEM was carried out using a Phillips 430 microscope operating at $300 \mathrm{kV}$. For this purpose material samples taken adjacent to the tube bore (the surface of reactants flow in one-sided deposition) were prepared by ion milling or by ultramicrotomy. For ion milling the samples were first mechanically thinned in a dimpler. For ultramicrotomy the samples were first vacuum impregnated with the precursor solution of an epoxy. After polymerization was completed, the sample was thinned by polishing and finally microtomed. This sample preparation procedure was based on the technique developed by Ehret et al. 2 Ultramicrotomy gives sections of uniform thickness, thus the transmission electron micrographs are readily interpretable for porosity variation. With ion milling one has to account for sample thickness variations making the interpretation of the micrographs complicated and uncertain. By comparing micrographs of untreated Vycor prepared by microtomy and ion milling it was found that microtomy does not introduce artifacts during sample preparation. For the analysis of the deposited layers only microtomed samples were used.

Image analysis was carried out using the technique of Levitz et al. ${ }^{3} \mathrm{~A}$ micrograph of a sample from an untreated Vycor tube is shown in Figure 3 at two different magnifications. The sample thickness is not uniform but varies in the range 10-30 nm. Because more than one pore can be accommodated within this thickness, and because the direction of the pores is random, the pore geometry cannot be clearly deduced. However, a rough idea about the size of the pores (about $50 \AA$ ) and the length of pore segments (about 150-200 $\AA$ ) may be obtained. A micrograph containing a $\mathrm{SiO}_{2}$ deposit layer (one-sided deposition) is shown in Figure 4. This micrograph indicates a residual (trapped) porosity by the bright contrast it creates. The residual void fraction is estimated at about $11 \%$ ( $40 \%$ of the initial) which corresponds to a $\mathrm{SiO}_{2}$ (deposit): $\mathrm{SiO}_{2}$ (support) ratio of about 0.24 , higher than the 0.17 estimated from the EMA scan. The difference is mainly due to the spatial averaging inherent in the low resolution EMA. We 
have recently performed thermogravimetric analysis (TGA) of $\mathrm{SiO}_{2}$ deposition providing an estimate of $25 \%$ for the $\mathrm{SiO}_{2}$ (deposit): $\mathrm{SiO}_{2}$ (support) ratio in close agreement with the value estimated from TEM. The trapped porosity indicated by SEM, TEM and TGA has a beneficial effect on membrane permeance by reducing the effective thickness of the deposit layer.

From several micrographs taken along a direction perpendicular to the bounding (bore) surface, it was found that within about $0.5 \mu \mathrm{m}$ from the bounding surface there is no significant variation of the residual (trapped) porosity. Thus the sublayer of maximum deposition, which provides the membrane separation selectivity, seems to be about 0.5 $\mu \mathrm{m}$ thick.

\section{Literature Cited}

1. Gavalas, G. R., Hydrogen Separation by Ceramic Membranes in Coal Gasification, California Institute of Technology final report to DOE-METC under contract DE-AC21-90MC26365, October 1992.

2. Ehret, G., Crovisier, J. L., and Eberhart, J. P., J. Noncrystalline Solids 86, 72 (1986).

3. Levitz, P., Ehret, G., Sinha, S. K., and Drake, J. M., J. Chem. Phys. 95, 8 (1991). 


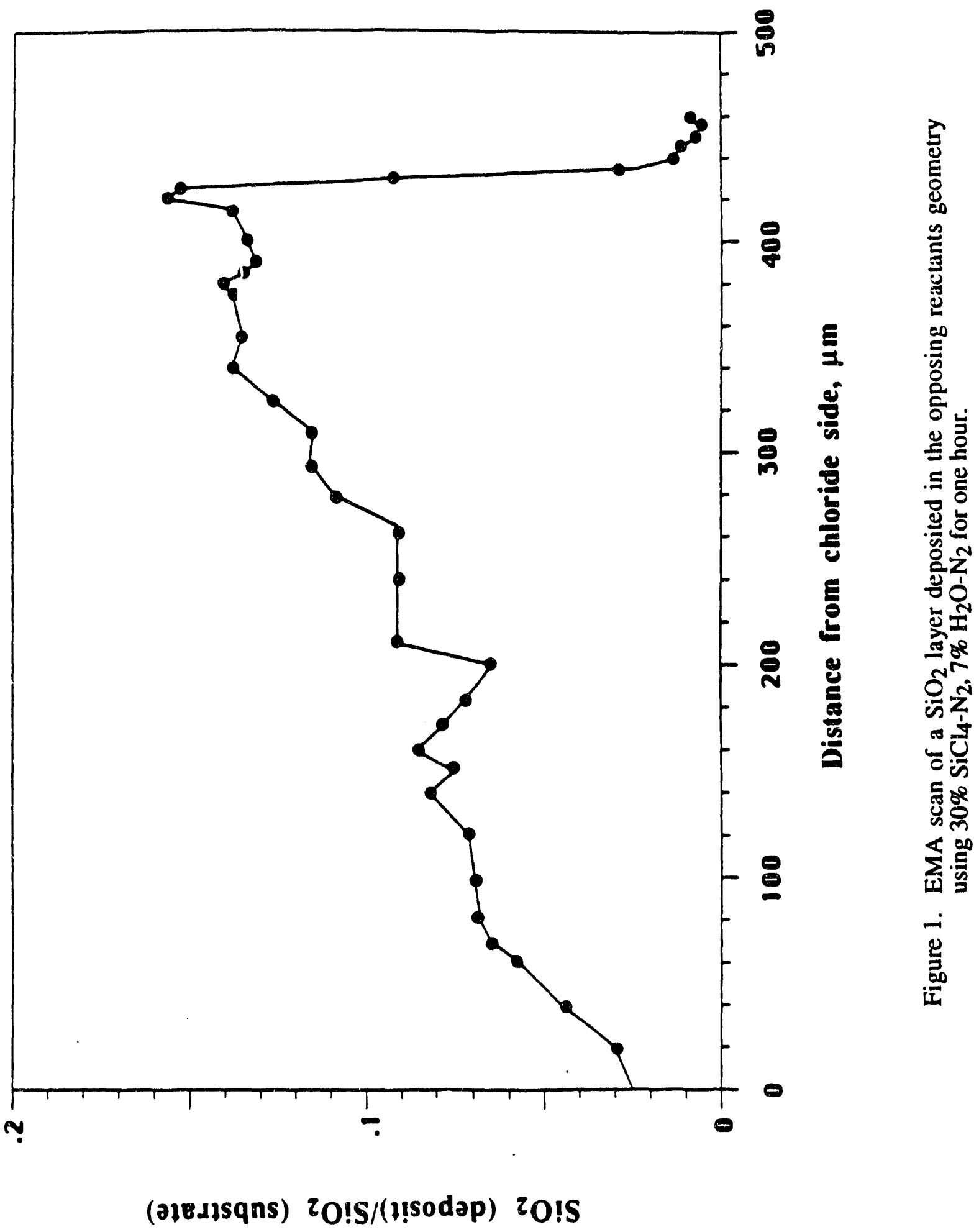




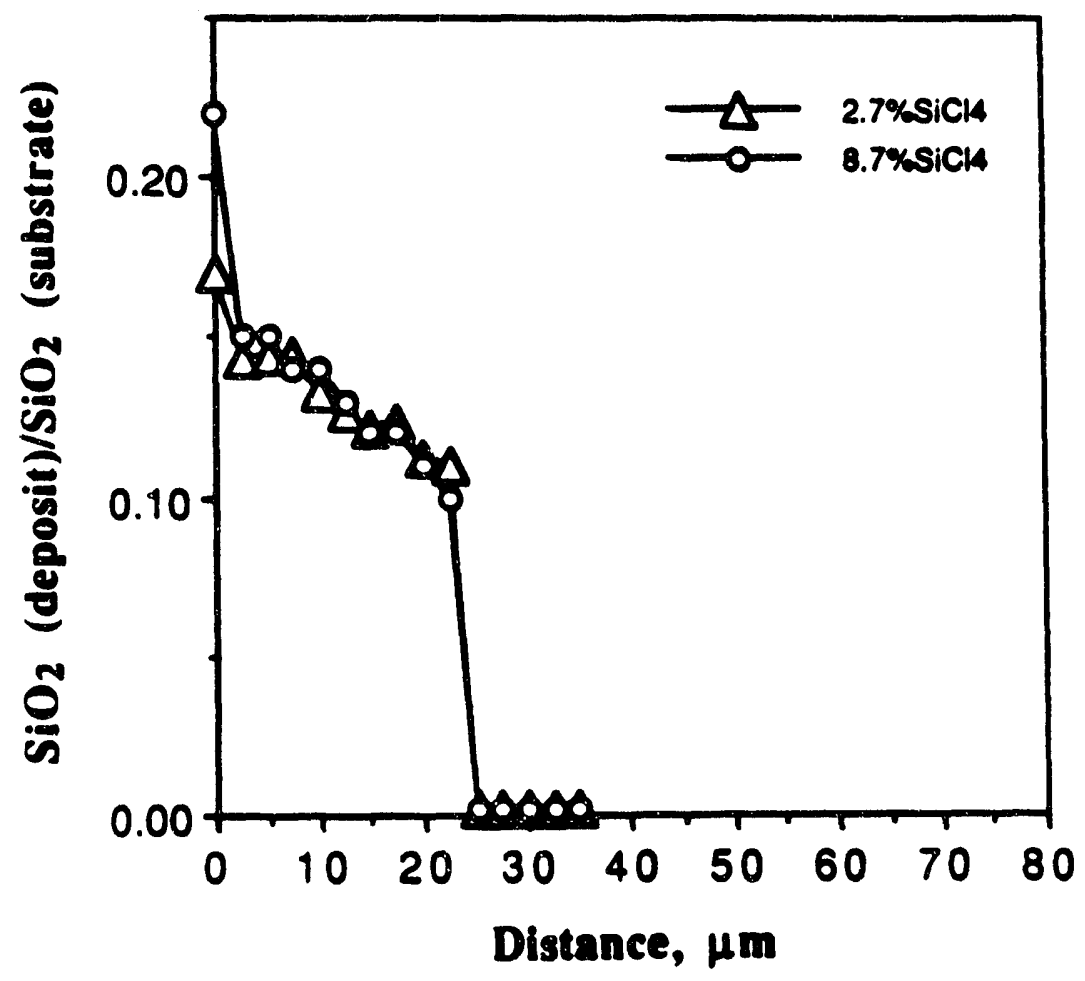

Figure 2. EMA of silica membranes deposited at $600^{\circ} \mathrm{C}$ in OSG with $13 \% \mathrm{H}_{2} \mathrm{O}$. 


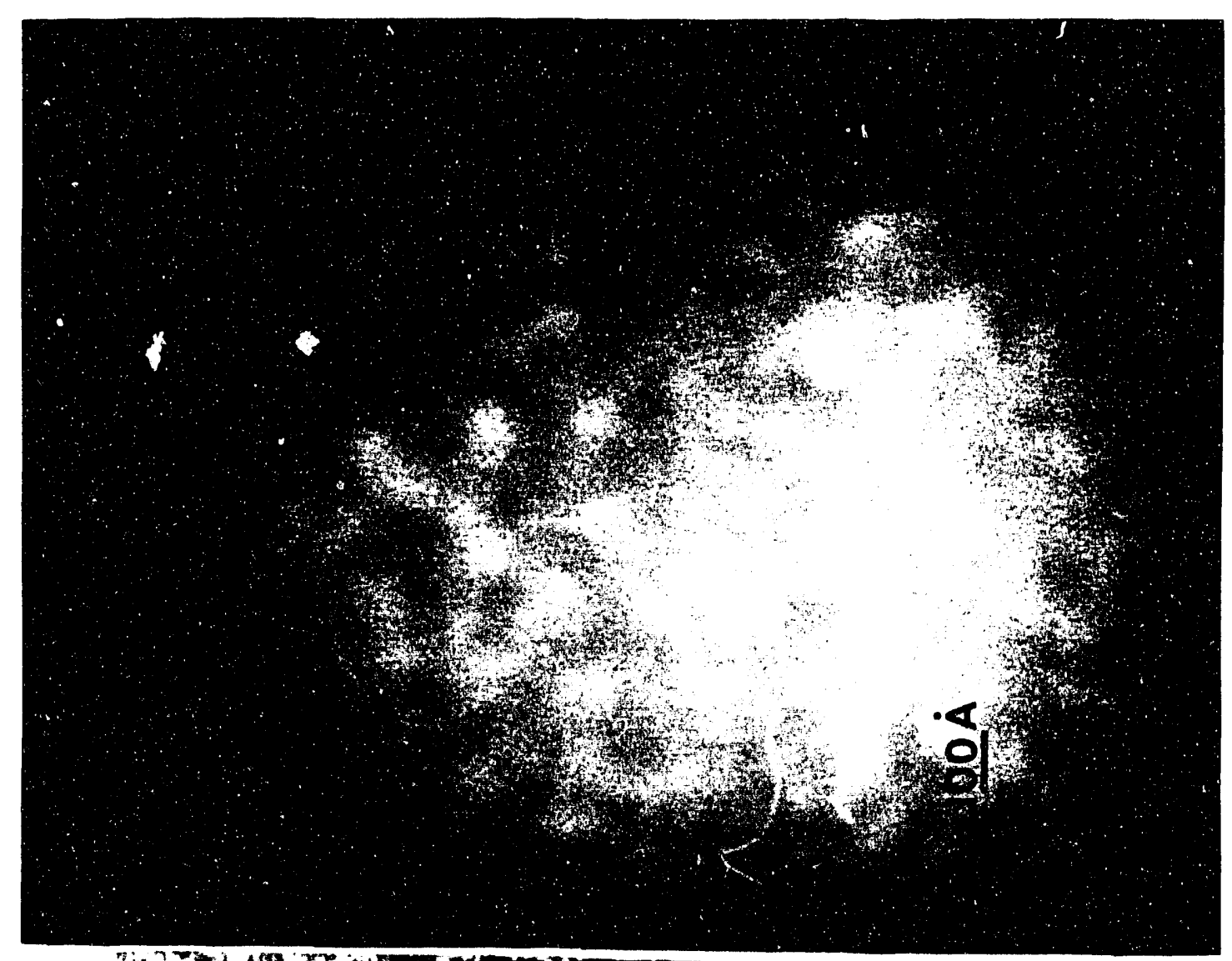

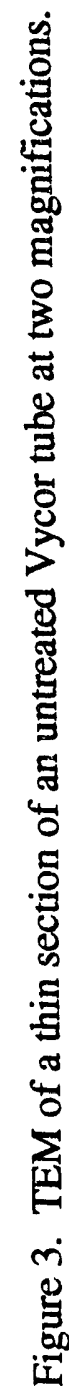

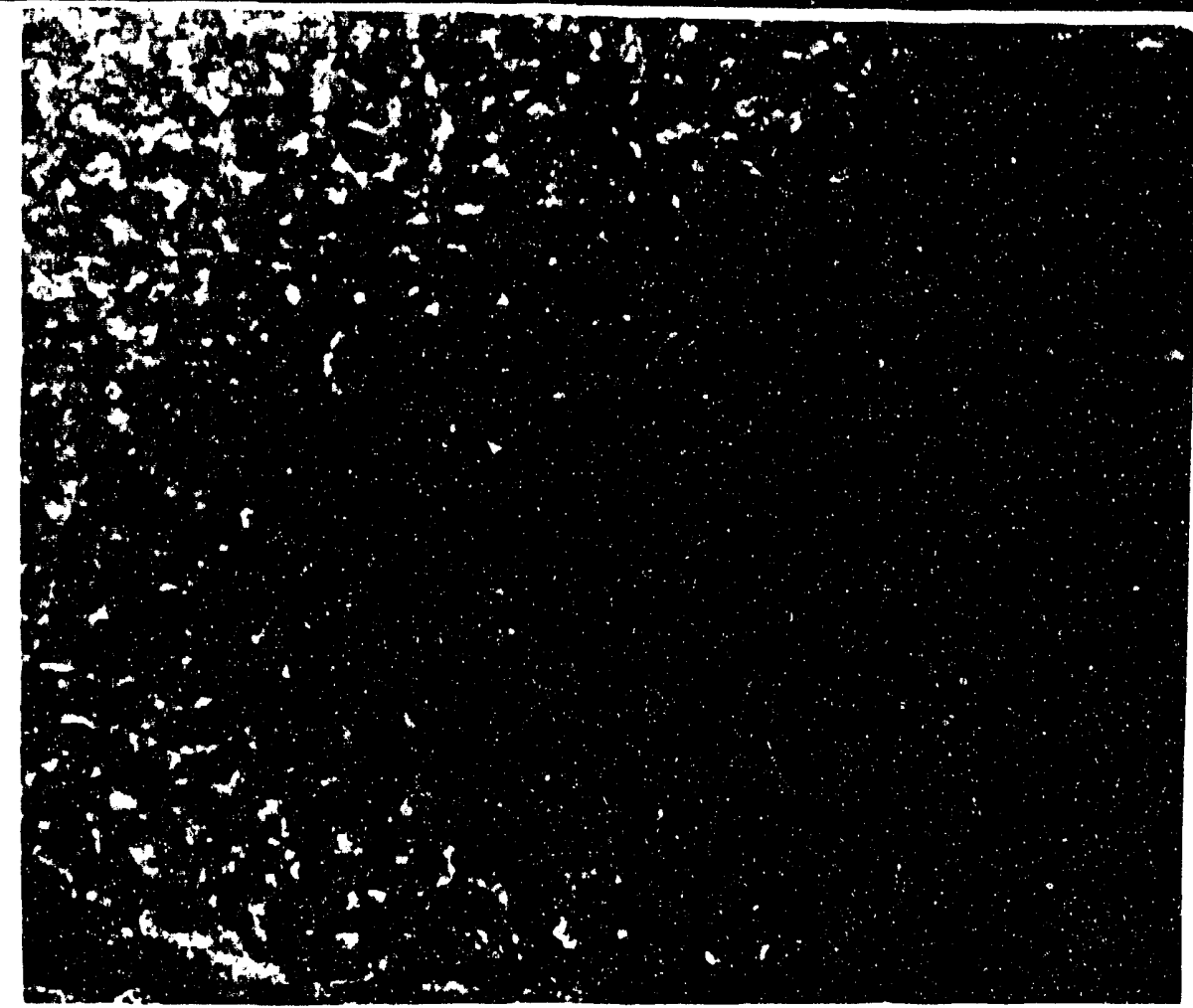




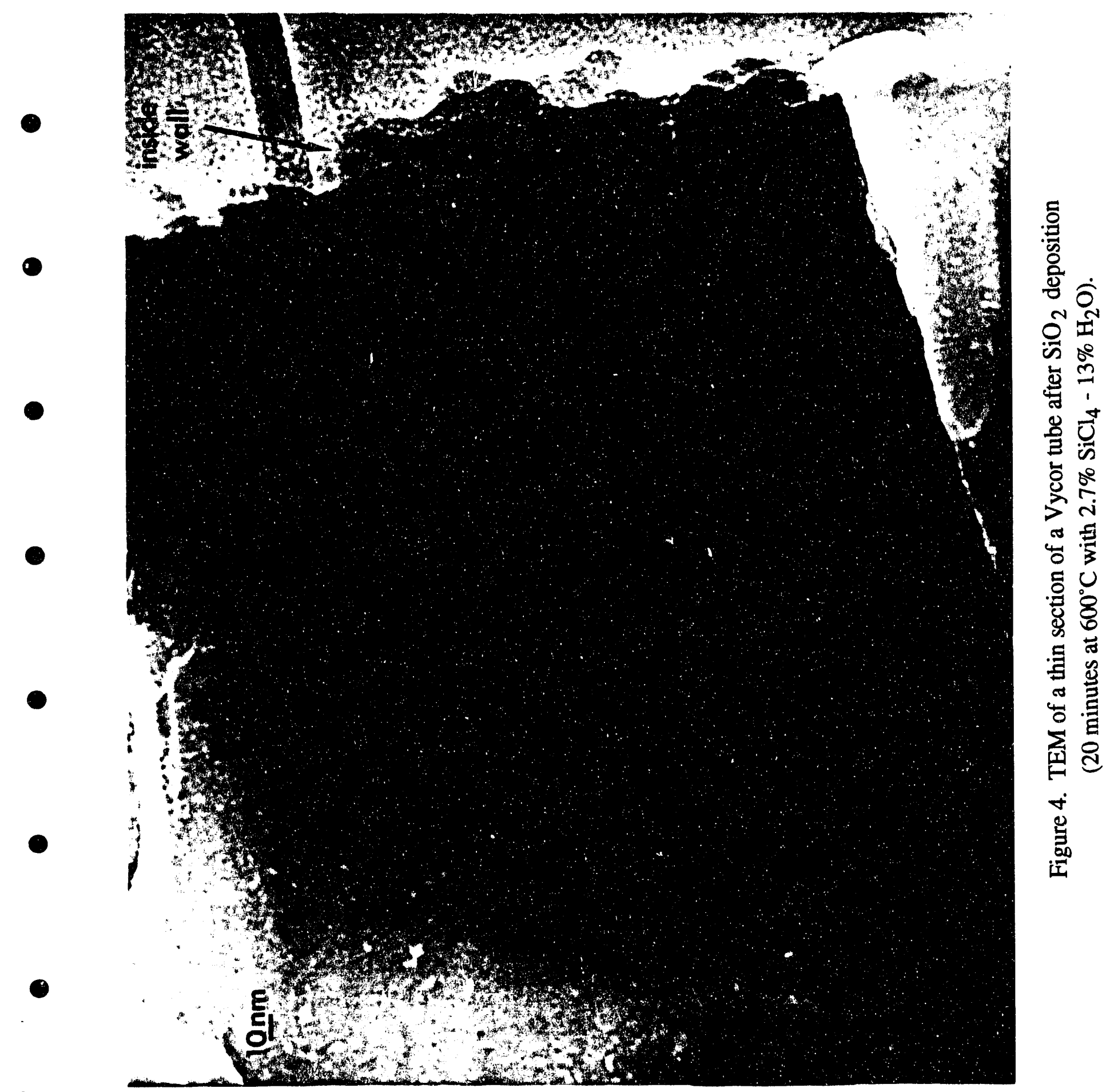




\section{Chapter 3}

\section{THERMOGRA VIMETRIC ANALYSIS OF THE REACTIONS OF SiCl4, TiCl4 AND H2O WITH THE VYCOR SURFACE}


As discussed in Chapter $1, \mathrm{SiO}_{2}$ deposition occurs by a heterogeneous mechanism involving the reaction of gaseous $\mathrm{SiCl}_{4}$ and surface hydroxyl groups, the reaction of gaseous $\mathrm{H}_{2} \mathrm{O}$ with surface chloride groups, and condensation reactions forming siloxane bridges:

$$
\begin{gathered}
\mathrm{Si}-\mathrm{OH}(\mathrm{s})+\mathrm{SiCl}_{4}(\mathrm{~g})=\mathrm{Si}-\mathrm{O}-\mathrm{SiCl}_{3}(\mathrm{~s})+\mathrm{HCl}(\mathrm{g}) \\
\mathrm{Si}-\mathrm{Cl}(\mathrm{s})+\mathrm{H}_{2} \mathrm{O}(\mathrm{g})=\mathrm{Si}-\mathrm{OH}(\mathrm{s})+\mathrm{HCl}(\mathrm{g}) \\
\mathrm{Si}-\mathrm{OH}(\mathrm{s})+\mathrm{Si}-\mathrm{OH}(\mathrm{s})=\mathrm{Si}-\mathrm{O}-\mathrm{Si}(\mathrm{s})+\mathrm{H}_{2} \mathrm{O}(\mathrm{g}) \\
\mathrm{Si}-\mathrm{OH}(\mathrm{s})+\mathrm{Si}-\mathrm{Cl}(\mathrm{s})=\mathrm{Si}-\mathrm{O}-\mathrm{Si}(\mathrm{s})+\mathrm{HCl}(\mathrm{g})
\end{gathered}
$$

The above reaction steps constitute a polymerization mechanism with final product $\mathrm{SiO}_{2}$. A similar mechanism applies to the formation of other oxide layers from the corresponding chlorides and $\mathrm{H}_{2} \mathrm{O}$. The reaction of $\mathrm{SiCl}_{4}$ and other chlorosilanes with silica surfaces has been stidied by several investigators [1-2]. Since most of these studies were concerned with measuring the concentrations of different types of hydroxyl groups on the silica surface, little has been reported about the kinetics of the silylation reactions, or the related hydrolysis of surface chloride groups. To understand the possibilities and limitations in membrane preparation it is important to obtain information about the kinetics of the silylation, hydrolysis, and condensation reactions, and about the role of operating váriables such as temperature, reactant concentrations, and thermal gretreatment of the support. In this chapter we summarize kinetic experiments perforned using a thermogravinetric analysis system (TGA). Experiments were conducted with both the $\mathrm{SiCl}_{4}-\mathrm{H}_{2} \mathrm{O}$ reactions and the $\mathrm{TiCl}_{4}-\mathrm{H}_{2} \mathrm{O}$ reactions but most of the discussion refers to the $\mathrm{SiCl}_{4}-\mathrm{H}_{2} \mathrm{O}$ reaction network.

During membrane preparation the Vycor surface is exposed to the two reactants $\mathrm{SiCl}_{4}$ and $\mathrm{H}_{2} \mathrm{O}$ (or $\mathrm{TiCl}_{4}$ and $\mathrm{H}_{2} \mathrm{O}$ ) simultaneously so that reactions (1)-(4) proceed in a highly coupled fashion. For the purpose of delineating the detailed kinetics, it is desirable to decouple as much as possible the various steps, hence, the two reactants 
$\mathrm{SiCl}_{4}$ and $\mathrm{H}_{2} \mathrm{O}$ were never present simultaneously but were introduced in alternating periods separated by periods of purge. When the Vycor surface is exposed to $\mathrm{SiCl}_{4}$, in the absence of water, reaction proceeds until all available silanols (surface hydroxyls) are exhausted. Likewise, when the silylated surface is exposed to water vapor, hydrolysis proceeds until all chloride groups are eliminated. During exposure of the surface with $\mathrm{SiCl}_{4}$, the main reaction (1) is accompanied by the slower reaction (3). During hydrolysis the main reaction (2) is accompanied by the slower reactions (3) and (4). A quantitative analysis of the coupled reactions taking into account the effect of external and pore diffusion is under way under a new DOE-UCR grant. The present report is limited to the presentation and qualitative discussion of the experimental results.

\subsection{Reactions of $\mathrm{SiCl}_{4}$ and $\mathrm{H}_{2} \mathrm{O}$ with $\mathrm{Vycor}$}

Kinetic measurements were conducted using a DuPont 951 thermogravimetric analyzer (TGA) interfaced to a microcomputer. A sample of powdered Vycor glass approximately $20 \mathrm{mg}$ and particle size below $100 \mu \mathrm{m}$ was placed as a thin layer on a quartz pan inside the quartz housing of the TGA, and exposed to a stream of the chlorosilane reactant in nitrogen, or to a stream of water vapor in nitrogen. The weight of the sample was measured continuously. The TGA system is illustrated schematically in Figure 1.

Before each reaction sequence the Vycor sample was pretreated by heating in $\mathrm{N}_{2}$ flow of $200 \mathrm{~cm}^{3} / \mathrm{min}$ at a specific pretreatment temperature (usually $600^{\circ} \mathrm{C}$ ) for 3 hours to stabilize the number of surface - $\mathrm{OH}$ groups. The sample was then brought to the reaction temperature and subjected to a stream of $9 \% \mathrm{SiCl}_{4}-\mathrm{N}_{2}$ at $250 \mathrm{~cm} 3 / \mathrm{min}$ flowrate. The silylation continued until the weight leveled off and was followed by a purge with a stream of $200 \mathrm{~cm}^{3} / \mathrm{min} \mathrm{N}_{2}$ for 0.5 hour to remove all traces of gaseous reactants and products from the TGA. The purge was followed by reaction with a stream of $7 \%$ $\mathrm{H}_{2} \mathrm{O}-\mathrm{N}_{2}$ at $250 \mathrm{~cm}^{3} / \mathrm{min}$ flowrate, and a purge with nitrogen at $200 \mathrm{~cm}^{3} / \mathrm{min}$ flowrate. 
Each complete cycle of silylation and hydrolysis with intermediate $\mathrm{N}_{2}$ purges was repeated two or three times.

Figure 2 shows the TGA trace for the first silylation period and the succeeding purge period. The silylation is initially rapid but levels off gradually. During the succeeding purge period, the weight decreased slowly. Figure 3 shows the hydrolysis and purge period following the silylation and purge of Figure 2. During hydrolysis the weight decreases further due to the replacement of $-\mathrm{Cl}$ groups by $-\mathrm{OH}$ groups. The general features of the second cycle of the reactions are similar to those of the first one. Figure 3 shows a TGA trace for two complete cycles of reaction with $\mathrm{SiCl}_{4}$ and $\mathrm{H}_{2} \mathrm{O}$. The silylation step (1) is very fast. More than $70 \%$ of the total weight increase was achieved within the first one half minute at $600^{\circ} \mathrm{C}$, but the rate was lower by about a factor of 3 at $450^{\circ} \mathrm{C}$. Figures 4 and 5 show traces for silylation + purge and hydrolysis + purge at $450^{\circ} \mathrm{C}$.

Table 1 summarizes the reaction time and weight change for silylation, purge, and hydrolysis at two reaction temperatures. The Vycor samples were pretreated at different temperatures to study the effect of the initial - $\mathrm{OH}$ concentration on the surface. In general the samples pretreated at higher temperature resulted in lower weight increase during silylation. Preheating clearly reduces the number of surface silanols which constitute the reactive sites for silylation (reaction 1).

Table 1. Weight changes in various parts of the reaction cycle for samples pretreated at different temperatures.

\begin{tabular}{cllcccc} 
Pretreatment T & Reaction T & $\begin{array}{c}\text { Reaction } \\
\text { time }\end{array}$ & $\begin{array}{c}\mathrm{S} \\
+\Delta \mathrm{m} \\
\%\end{array}$ & $\begin{array}{c}\mathrm{P} \\
-\Delta \mathrm{m} \\
\%\end{array}$ & $\begin{array}{c}\mathrm{H} \\
\boldsymbol{\%}\end{array}$ & $\begin{array}{c}\mathrm{P} \\
\%\end{array}$ \\
\hline & & & & & & \\
$800^{\circ} \mathrm{C}$ & $600^{\circ} \mathrm{C}$ & $2 \mathrm{~min}$ & 2.4 & 0.53 & 0.66 & 0.13 \\
$600^{\circ} \mathrm{C}$ & $600^{\circ} \mathrm{C}$ & $2 \mathrm{~min}$ & 4.4 & 0.56 & 1.67 & 0.14 \\
$600^{\circ} \mathrm{C}$ & $450^{\circ} \mathrm{C}$ & $6 \mathrm{~min}$ & 4.6 & 0.15 & 2.03 & 0.29 \\
$450^{\circ} \mathrm{C}$ & $450^{\circ} \mathrm{C}$ & $6 \mathrm{~min}$ & 5.5 & 0.26 & 2.43 & 0.38
\end{tabular}

S: silylation; P: purge; H: hydrolysis 
It had been previously suggested that silylation may also take place in the absence of -OH groups by means of siloxane bridge opening,

$$
\mathrm{SiCl}_{4}+\mathrm{Si}-\mathrm{O}-\mathrm{Si}=\mathrm{Si}-\mathrm{Cl}+\mathrm{Si}-\mathrm{O}-\mathrm{SiCl}_{3}
$$

Our experiments indicate that this direct silylation, if it occurs at all, is extremely slow.

The weight decrease during the purge period following silylation can be explained by the consecutive reactions of the chloride groups on the surface with neighboring surface - $\mathrm{OH}$ groups:

$$
-\mathrm{O}-\mathrm{SiCl}_{3}+-\mathrm{OH}=\mathrm{O}-\mathrm{Si}-\mathrm{O}+\mathrm{HCl}(\mathrm{g})
$$

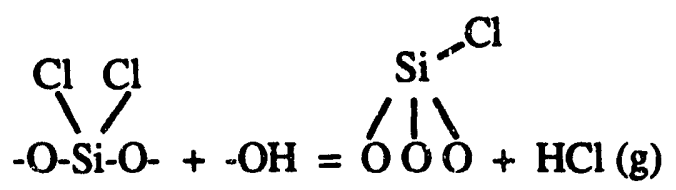

(these reactions are elaborations of reaction step (3)) which is consistent with our observation that when the purge was prolonged, the weight loss during the subsequent hydrolysis declined. This decline suggests the loss of surface chloride groups available for hydrolysis during the preceding $\mathrm{N}_{2}$ purge.

Further confirmation of the role of reactions (6) and (7) was obtained by an experiment using $\mathrm{Si}\left(\mathrm{CH}_{3}\right)_{3} \mathrm{Cl}$ instead of $\mathrm{SiCl}_{4}$. The silylation reaction in this case can be written as

$$
-\mathrm{OH}+\mathrm{Si}\left(\mathrm{CH}_{3}\right)_{3} \mathrm{Cl}(\mathrm{g})=-\mathrm{O}-\mathrm{Si}\left(\mathrm{CH}_{3}\right)_{3}+\mathrm{HCl}(\mathrm{g})
$$

whereupon there is no opportunity for subsequent reactions like (6) and (7). In this experiment, silylation was slower, and there was no weight decrease during the purge period. 
The rate of reactions (6) and (7) depends on the concentration of the chloride groups and that of the neighboring $-\mathrm{OH}$ groups. This is shown in Table 1 when one compares two samples pretreated at different temperatures. The weight decrease during the purge succeeding silylation is higher for the sample pretreated at the lower temperature.

The reactions (6) and (7) take place during the silylation period and continue through the succeeding purge period. A more detailed examination of the results shows that silylation (reaction (1)) is fast but does not proceed with ail surface -OH groups at the same rate. When one of two neighboring - $\mathrm{OH}$ groups has reacted according to (1), the rate of further reaction of gaseous $\mathrm{SiCl}_{4}$ with the neighboring unreacted $-\mathrm{OH}$ group is much lower, because of steric hindrance, and becomes comparable with the rate of reactions (6) and (7). The second silylation step, therefore, is in competition with the condensation reactions. This competition can be verified by the comparison of two experiments shown in Figure 7. Curve A corresponds to the weight change of a sample subjected to 30 minutes of continuous $\mathrm{SiCl}_{4}$ flow. Most of the weight gain was achieved during the first 2 minutes. The weight slowly increased during the next 28 minutes, which shows that silylation after the first rapid period was taking place at a much slower rate. The $-\mathrm{OH}$ groups that react at the slower rate are, evidently, sterically hindered. Curve $\mathrm{B}$ is the trace of a sample subjected to two minutes of $\mathrm{SiCl}_{4}$ flow, followed by 15 minutes of purge, followed by another $\mathrm{SiCl}_{4}$ flow of nearly 30 minutes. As in the case of curve A, the large weight gain during the first two minutes is due to the silylation of fast reacting $-\mathrm{OH}$ groups. During the succeeding purge, there is enough time for condensation reactions (6) and (7) to proceed without competition from additional silylation. When gaseous $\mathrm{SiCl}_{4}$ is introduced again, the weight increase during the 30 minutes of additional silylation is less than that of case $\mathrm{A}$, since a large fraction of the $-\mathrm{OH}$ groups remaining after the first silylation was consumed by the reactions (6) and (7) 
during the intermediate purge. Figure 8 shows the results of the same experiments in an expanded time scale.

The weight loss during reaction with $\mathrm{H}_{2} \mathrm{O}$ is due mainly to the hydrolysis of surface chloride groups by gaseous water (reaction 2). This reaction is slower than silylation. At $600^{\circ} \mathrm{C}$, for example, the major weight loss under flow of $7 \% \mathrm{H}_{2} \mathrm{O}-\mathrm{N}_{2}$ lasted 2-3 minutes compared to the 0.5 minute taken by silylation with $10 \% \mathrm{SiCl}_{4}-\mathrm{N}_{2}$. Simultaneously with hydrolysis the even slower condensation reactions (3) and (4) also contribute to the weight loss. The condensation reaction (3) continues beyond the hydrolysis period into the final purge period.

In one experiment, repeated cycles of silylation and hydrolysis with intermediate $\mathrm{N}_{2}$ purge were conducted until there was no more weight gain during the silylation step. This freezing of the reaction evidently occurs when the pore plugging due to $\mathrm{SiO}_{2}$ accumulation was sufficiently advanced to stop further diffusion of the reactants into the particle interior. This disruption of connectivity takes place while there is still considerable void volume which is inaccessible to $\mathrm{SiCl}_{4}$, as expected from percolation theory (the reaction that continues on the external particle surface makes a negligible contribution to the sample weight). As shown in Figure 9, the weight of the Vycor sample initially increased almost linearly and then leveled off after the tenth cycle. The total weight after 20 cycles was greater than the initial weight by approximately $24 \%$. Given the initial void fraction of 0.3 of the sample, complete pore filling by material having the true (skeletal) density of Vycor (2.18) would give a 43\% weight gain. The lower weight gain measured after 20 complete cycles is partly due to the lower density of the highly defective $\mathrm{SiO}_{2}$ deposit, and partly due to the trapped inaccessible porosity remaining after the disruption of pore connectivity.

Figure 10 shows the weight changes during silylation and hydrolysis for each of the twenty consecutive cycles. Consistently with the weight trace shown in Figure 9, the weight changes for silylation and hydrolysis decreased with successive reaction cycles. 
One interesting detail is that while the weight increase for the second and third silylation periods is less than that of the first, the weight decrease of the second and third hydrolysis periods is not much less, and in some cases is greater than that of the first. This may be explained by taking into account the location and accessibility of the reactive groups in the deposit layer. During the first silylation all silanol groups are on the surface and, therefore, accessible to the bulky $\mathrm{SiCl}_{4}$ molecule. In subsequent silylations the silanol groups at the top layer are accessible, but the groups buried in subsurface layers are increasingly inaccessible. With the area of the top layer decreasing with the deposition of additional layers, the number of $-\mathrm{OH}$ groups accessible to $\mathrm{SiCl}_{4}$ decreases. $\mathrm{By}$ contrast, during hydrolysis, the small water molecules can penetrate and react with chloride groups in subsurface layers as well as in the top layer. Similarly, the condensation of silanol groups can take place with little obstruction throughout the deposit. The extent of both of these reactions can increase with the number of deposit layers, although this increase is expected to taper off after the second or third layers because the number of reactive groups in any given layer decreases with time.

\subsection{Reactions of $\mathrm{TiCl}_{4}$ and $\mathrm{H}_{2} \mathrm{O}$ with $\mathrm{Vycor}$}

The experimental procedure used for the alternating reactions with $\mathrm{TiCl}_{4}$ and $\mathrm{H}_{2} \mathrm{O}$ was the same as the one for $\mathrm{SiCl}_{4}$ and $\mathrm{H}_{2} \mathrm{O}$ with the difference that reaction with $\mathrm{TiCl}_{4}$ was conducted using a mixture $5 \% \mathrm{TiCl}_{4}-\mathrm{N}_{2}$ and hydrolysis with a mixture $7 \% \mathrm{H}_{2} \mathrm{O}-\mathrm{N}_{2}$. Reaction with $\mathrm{TiCl}_{4}$ was carried out at 200,450 and $600^{\circ} \mathrm{C}$.

Figures 11-16 show TGA traces for three complete cycles of chlorination (reaction with $\mathrm{TiCl}_{4}$ ), purge, hydrolysis, and purge at $450^{\circ} \mathrm{C}$ for a Vycor sample previously pretreated at $450^{\circ} \mathrm{C}(\mathrm{V} 450)$. Chlorination is initially rapid but later levels off gradually (Figure 11). After 18.5 minutes, the $\mathrm{TiCl}_{4}$ flow was interrupted and $\mathrm{N}_{2}$ purge continued for another 21 minutes during which the weight slowly decreased. At the end of the purge period the weight had not yet reached a constant level. At that point 
hydrolysis commenced upon which the weight decreased relatively rapidly as shown in Figure 12. Figures 13-16 show a second and third complete cycle of the chlorinationpurge and hydrolysis-purge reaction. Qualitatively the results are similar as those of the first cycle. Hydrolysis took about 3 minutes versus the 10 minutes of chlorination, despite the fact that the volume fractions of $\mathrm{TiCl}_{4}$ and $\mathrm{H}_{2} \mathrm{O}$ were the same during chlorination and hydrolysis.

Figures 17-20 show two complete cycles of reactions with $\mathrm{TiCl}_{4}$ and $\mathrm{H}_{2} \mathrm{O}$ at $450^{\circ} \mathrm{C}$ of a Vycor sample pretreated at $600^{\circ} \mathrm{C}$. The results are similar to those of 11-16 except that the shape of the weight trace during chlorination becomes flatter more rapidly following the initial period of rapid increase. Figures 21-24 show two complete cycles of reaction at $600^{\circ} \mathrm{C}$ of sample $\mathrm{V} 600$. The reactions now are faster, but the other features of the traces remain very similar to those of 17-20. Figures 25-30 show three complete cycles of reaction at $200^{\circ} \mathrm{C}$ of the same sample, V600. The reactions are somewhat slower, but the traces are qualitatively similar to those in Figures 17-24.

Comparison of the reactions between $\mathrm{SiCl}_{4}$ and $\mathrm{TiCl}_{4}$ with $-\mathrm{OH}$ groups shows that the reaction of $\mathrm{TiCl}_{4}$ is about five times slower than that of $\mathrm{SiCl}_{4}$-after having taken into account the different concentrations used for the two reactants. During the purge following reaction with $\mathrm{TiCl}_{4}$ the weight decreases as in the reaction of $\mathrm{SiCl}_{4}$ showing the presence of condensation reactions similar to those depicted by Equations (6) and (7).

\section{Literature Cited}

1. Hair, M. L. and W. Hertl, Chlorination of Silica Surfaces, J. Phys. Chem. 77, 2070 (1973).

2. Hair, M. L. and W. Hertl, Reactions of Chlorosilanes with Silica Surfaces, J. Phys. Chem. 73, 2372 (1969). 


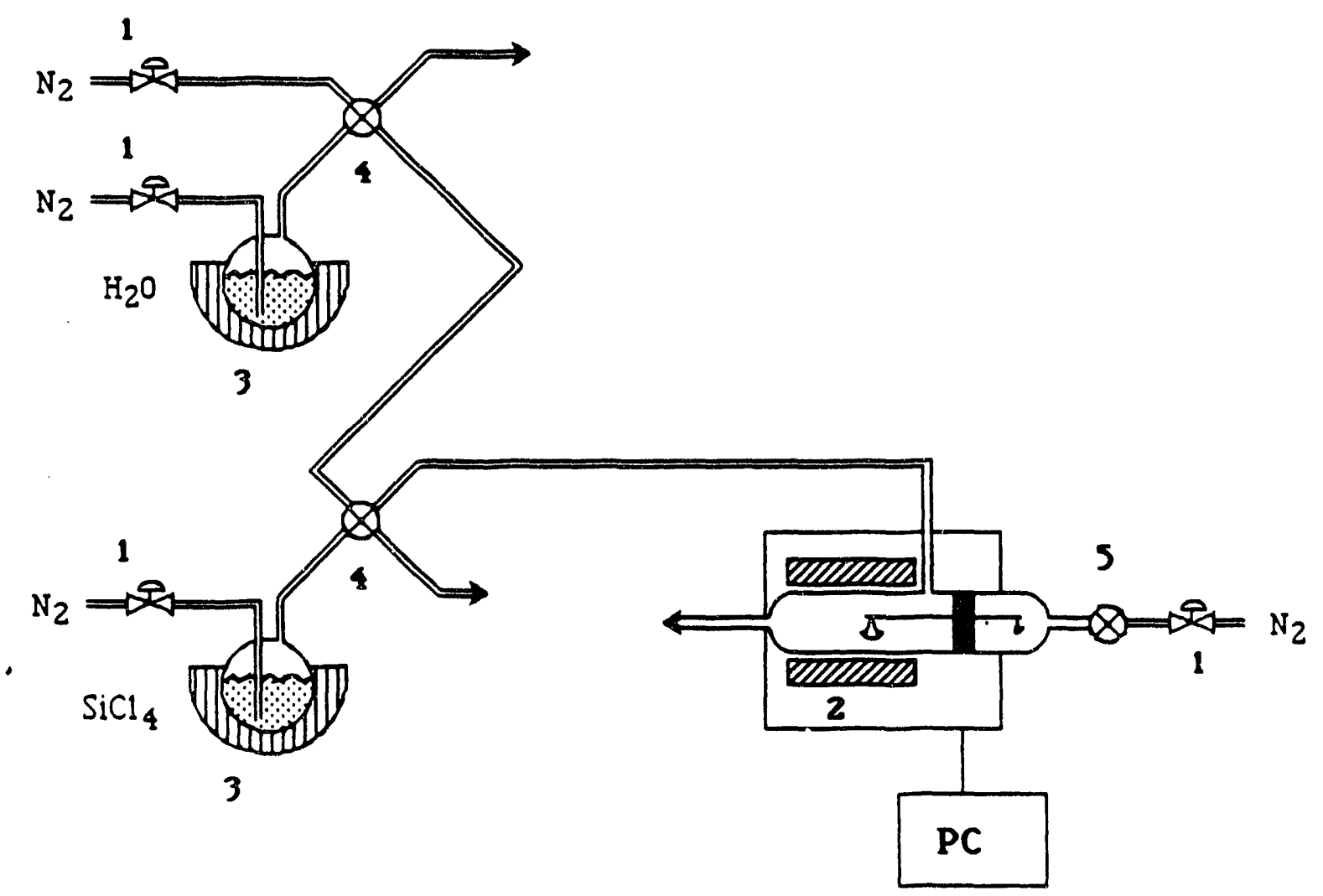

Figure 1. Schematic diagram of TGA system:

1. mass flowmeter with valve; 2 . furnace with temperature controller;

3. bubbler with heating element and temperature controller;

4. 4-way value; 5. on-off valve. 


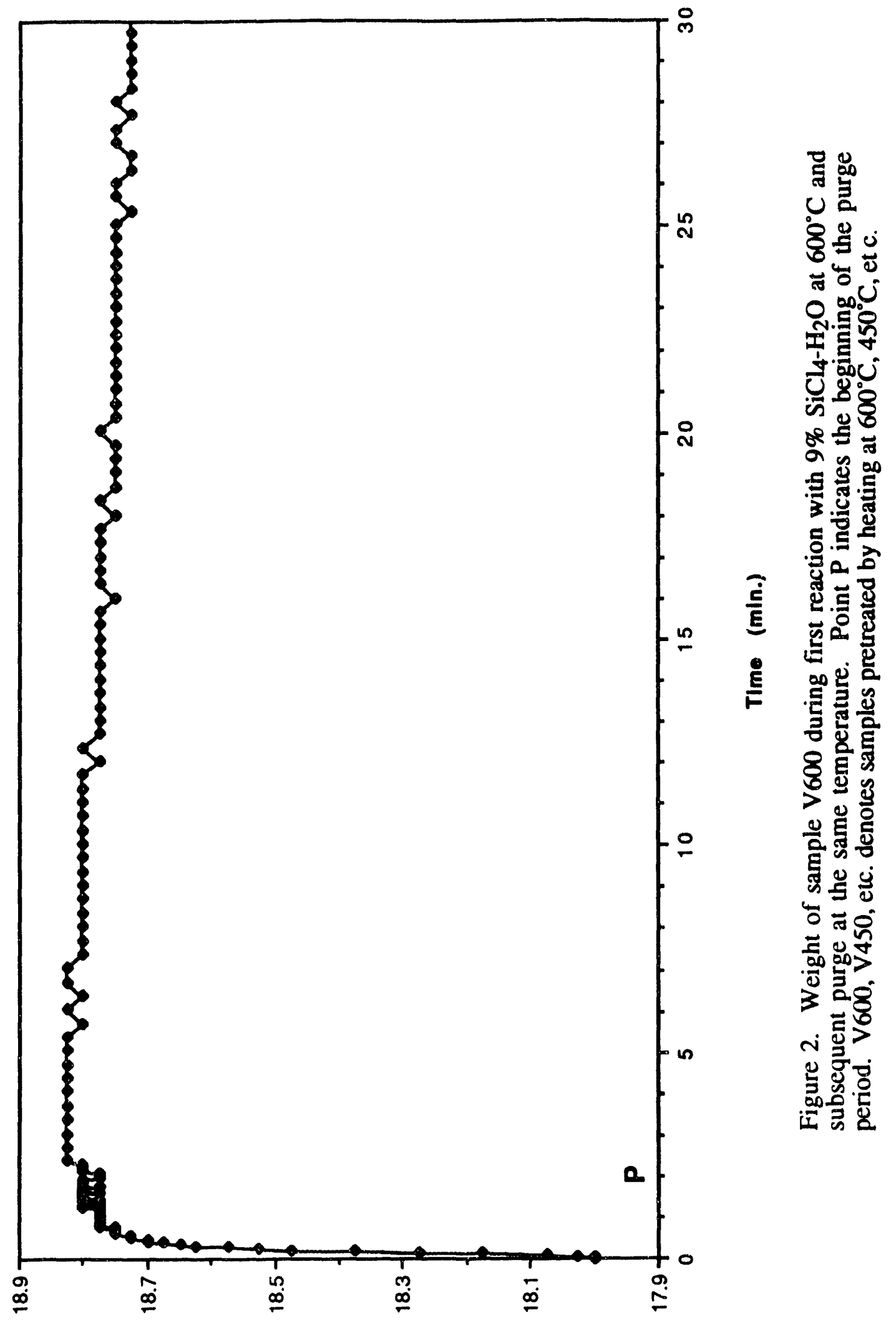

[

(6u) $14810 \mathrm{M}$ 


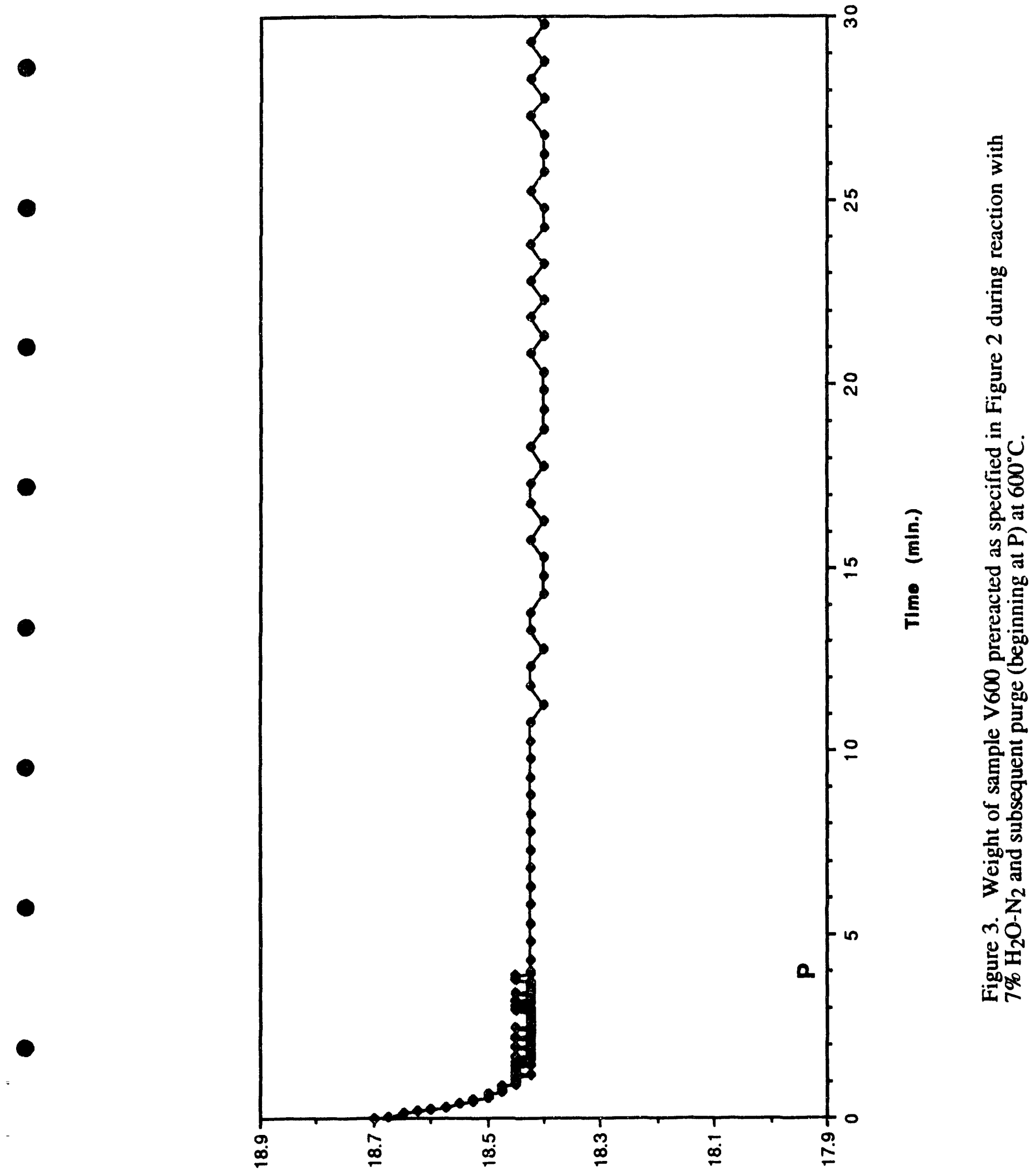

(6ui) $14610 \mathrm{M}$ 


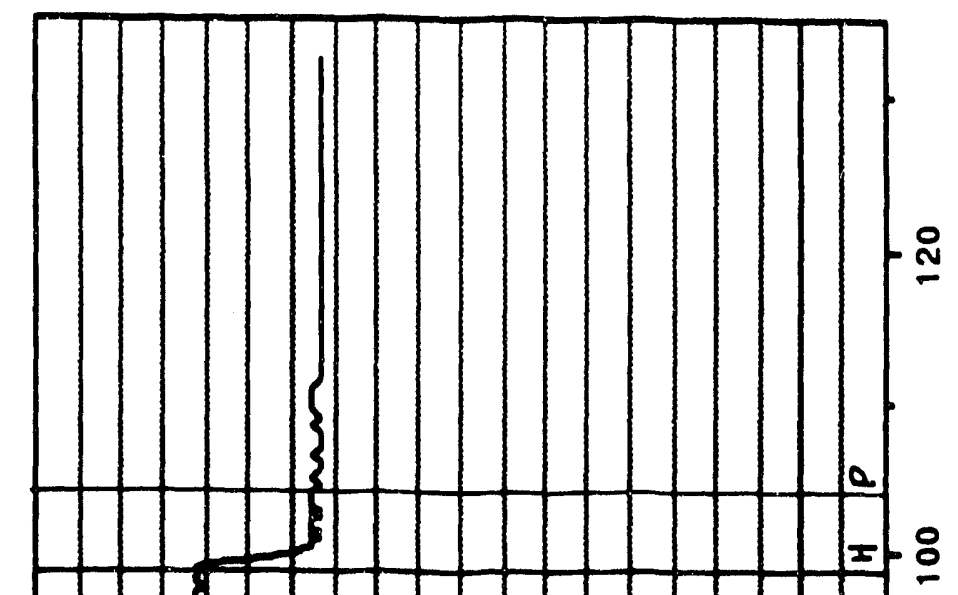

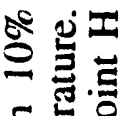

들 욜.

ธี ญ्य

苞范

记

동

บิ

रेख

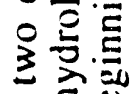

8
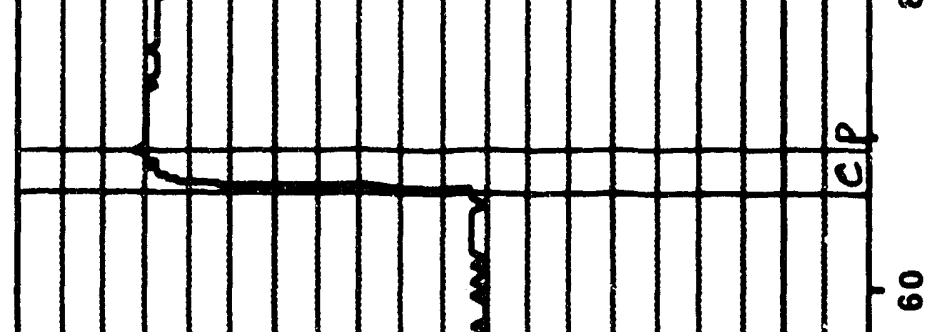

$:$

五马三

电牙

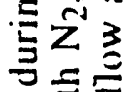

高交

i $\quad 2$

E E
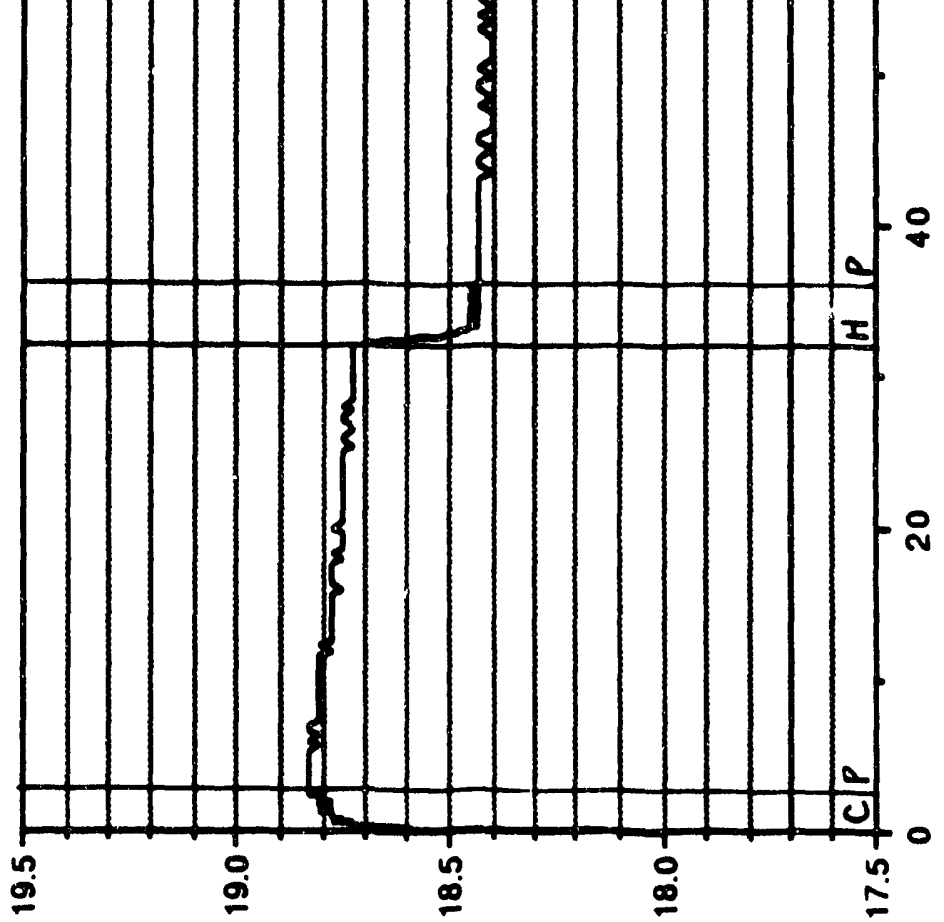

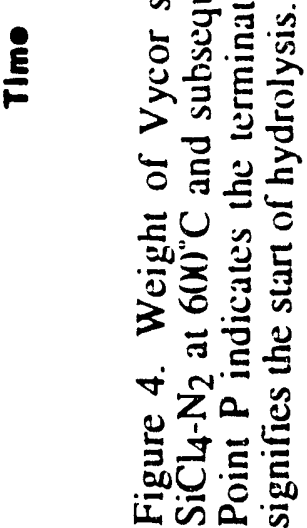

I

(Bw) $14010 M$ 


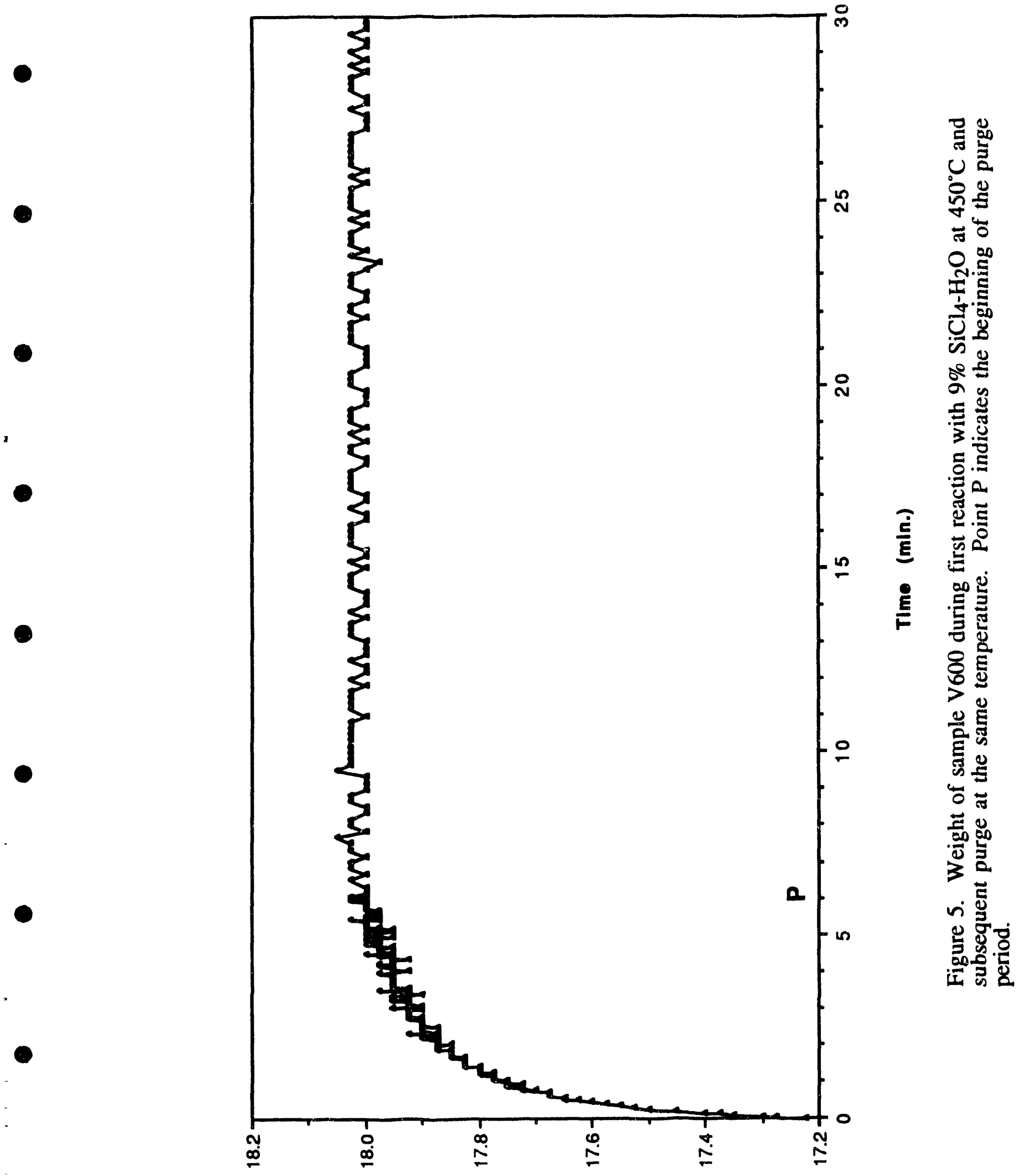

(Bu) $148 / 0 M$ 


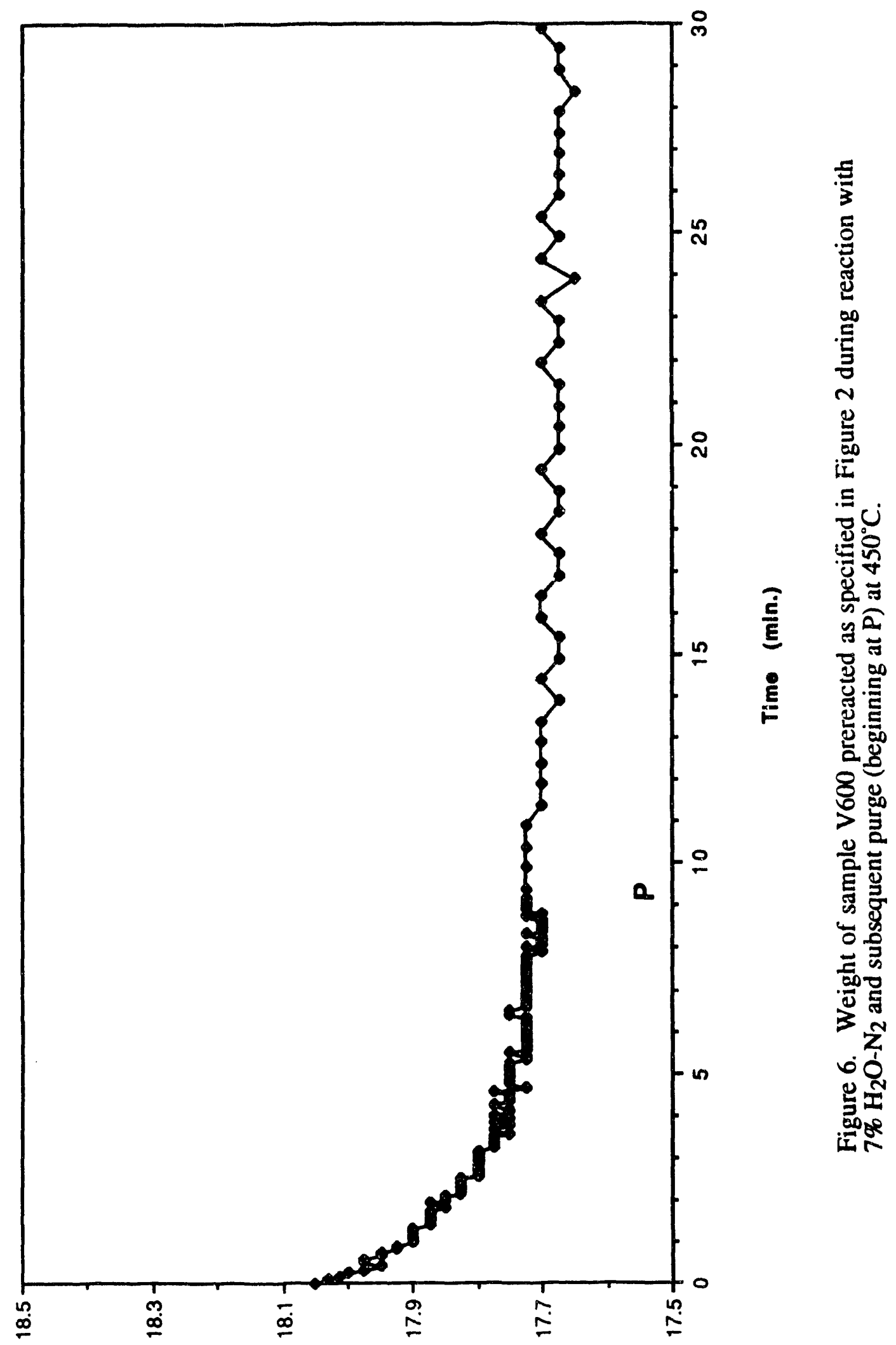

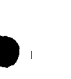




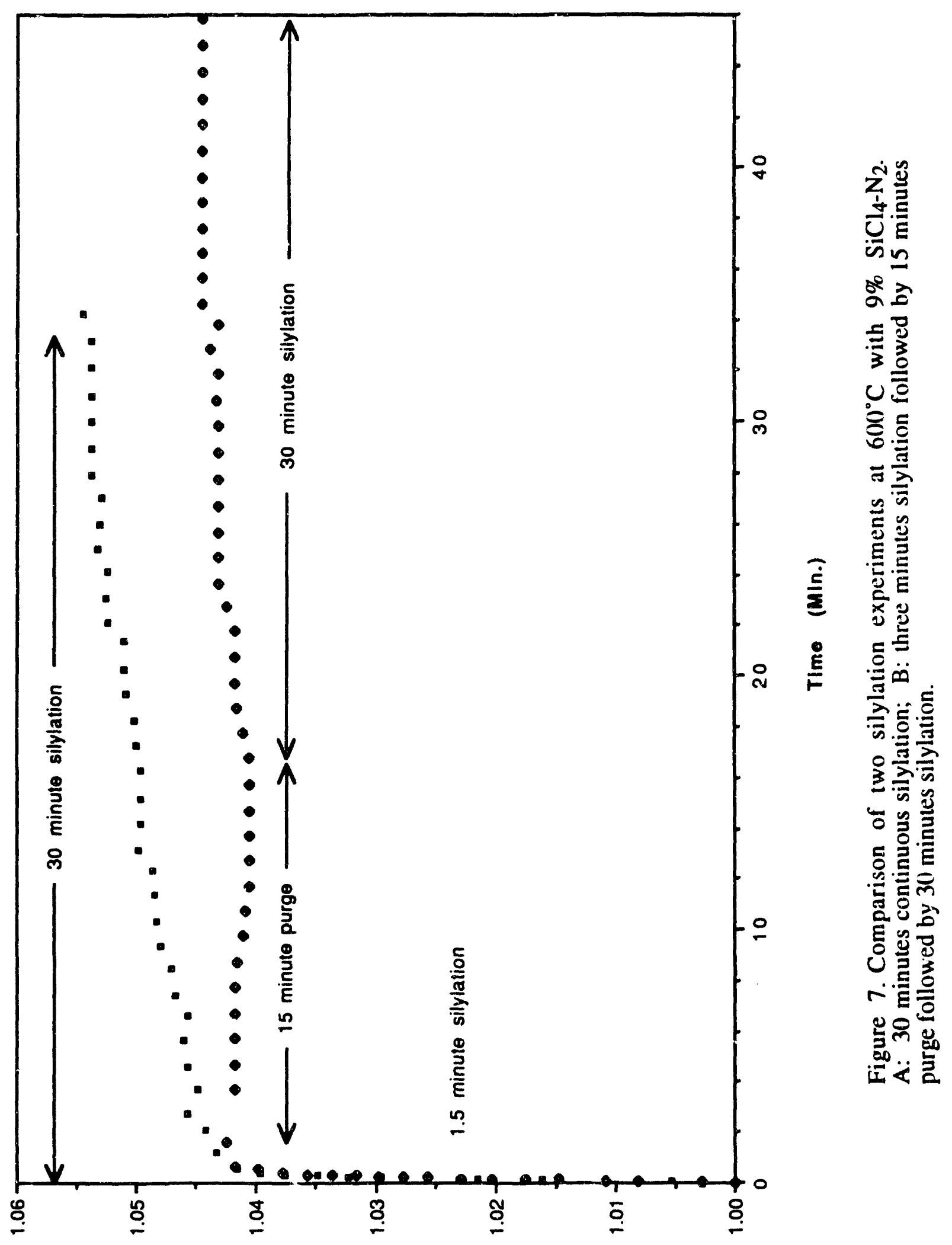

14610M pozIIELION 


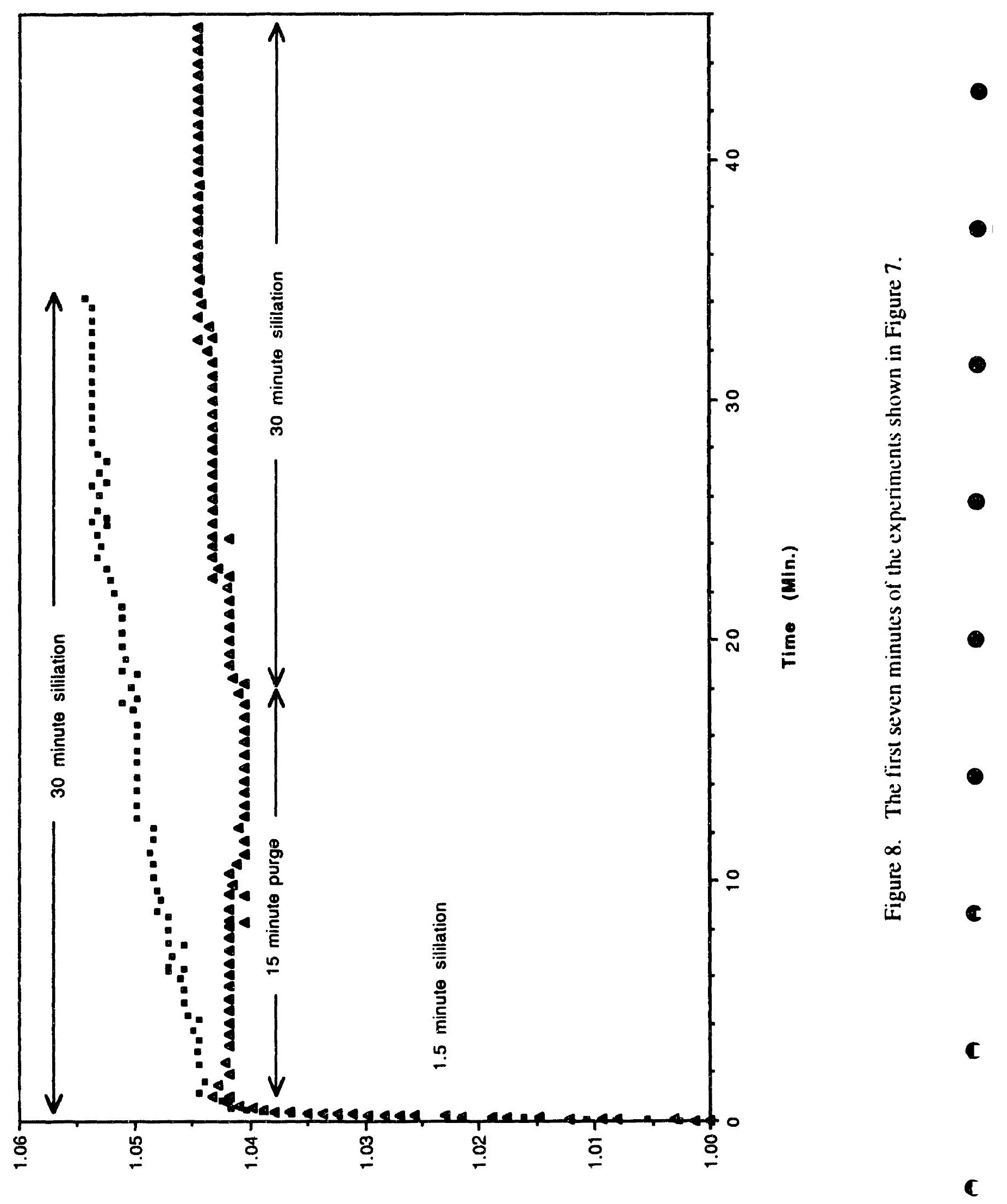

I4610M pozाleuson 


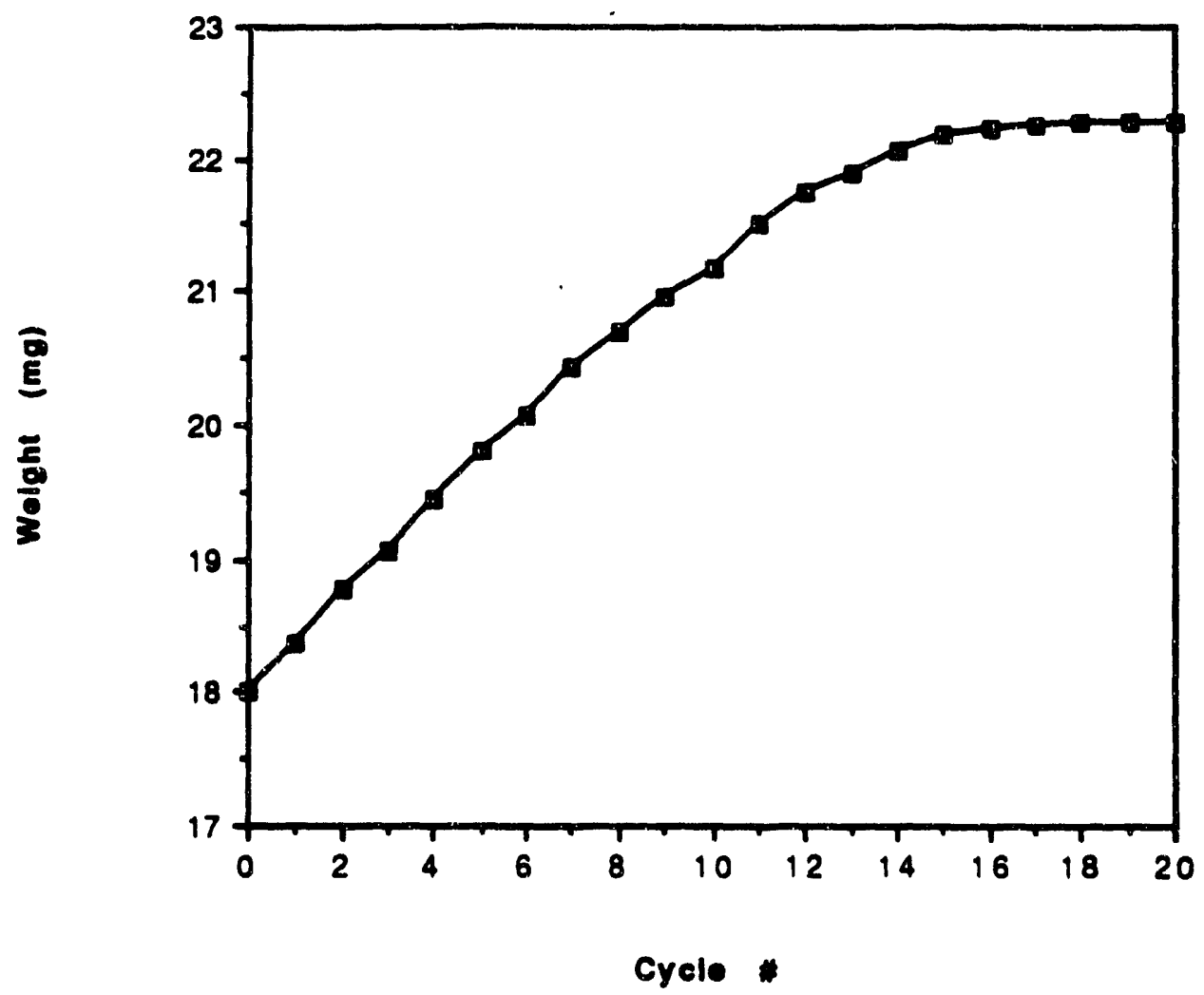

Figure 9. Weight of Vycor sample V600 during 20 consecutive cycles of silylation, purge, hydrolysis, purge. (Reactions carried out under conditions of Figures 2 and 3 ). 


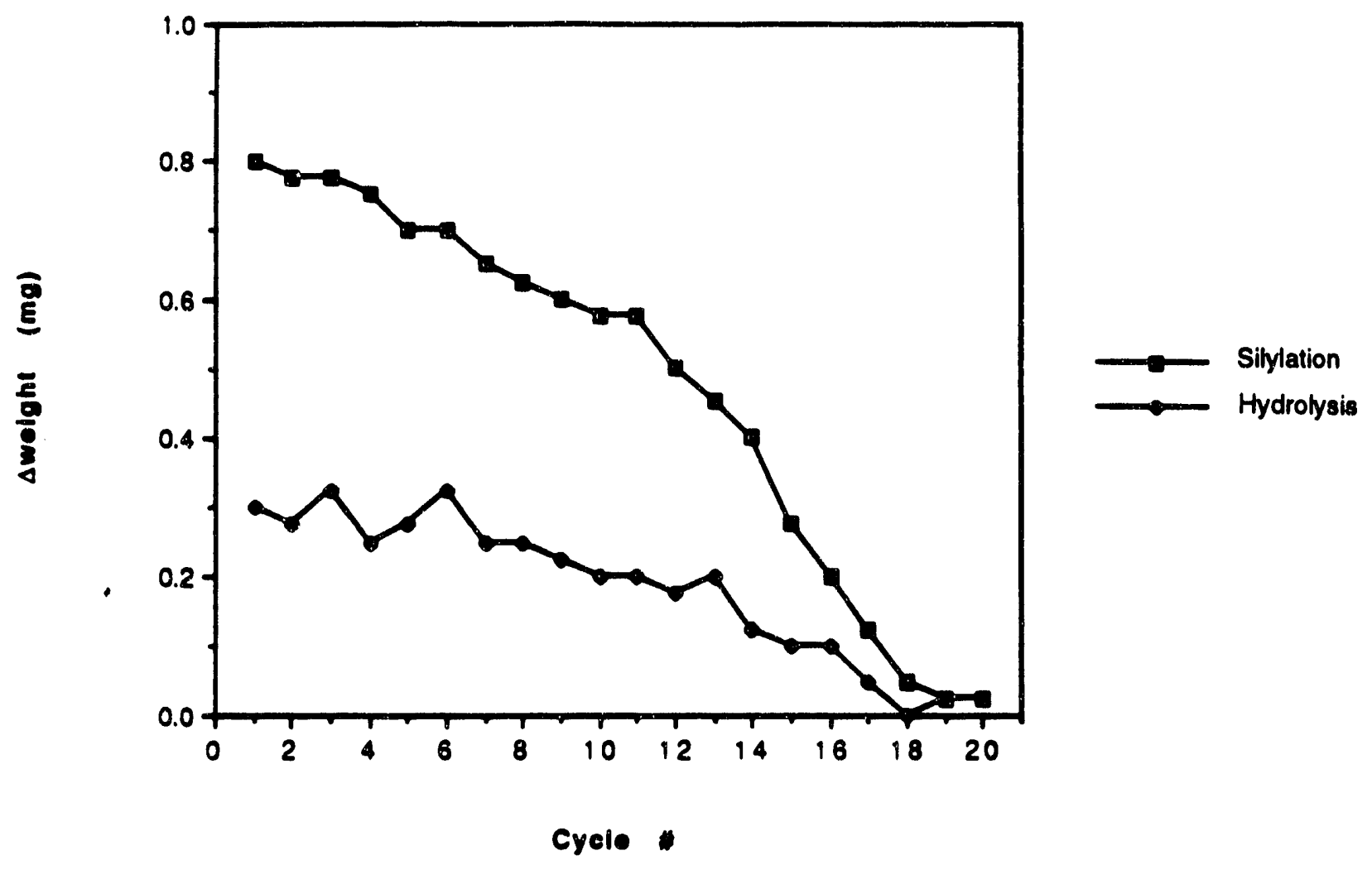

Figure 10. Weight change for each of the 20 consecutive cycles of silylation and hydrolysis. 


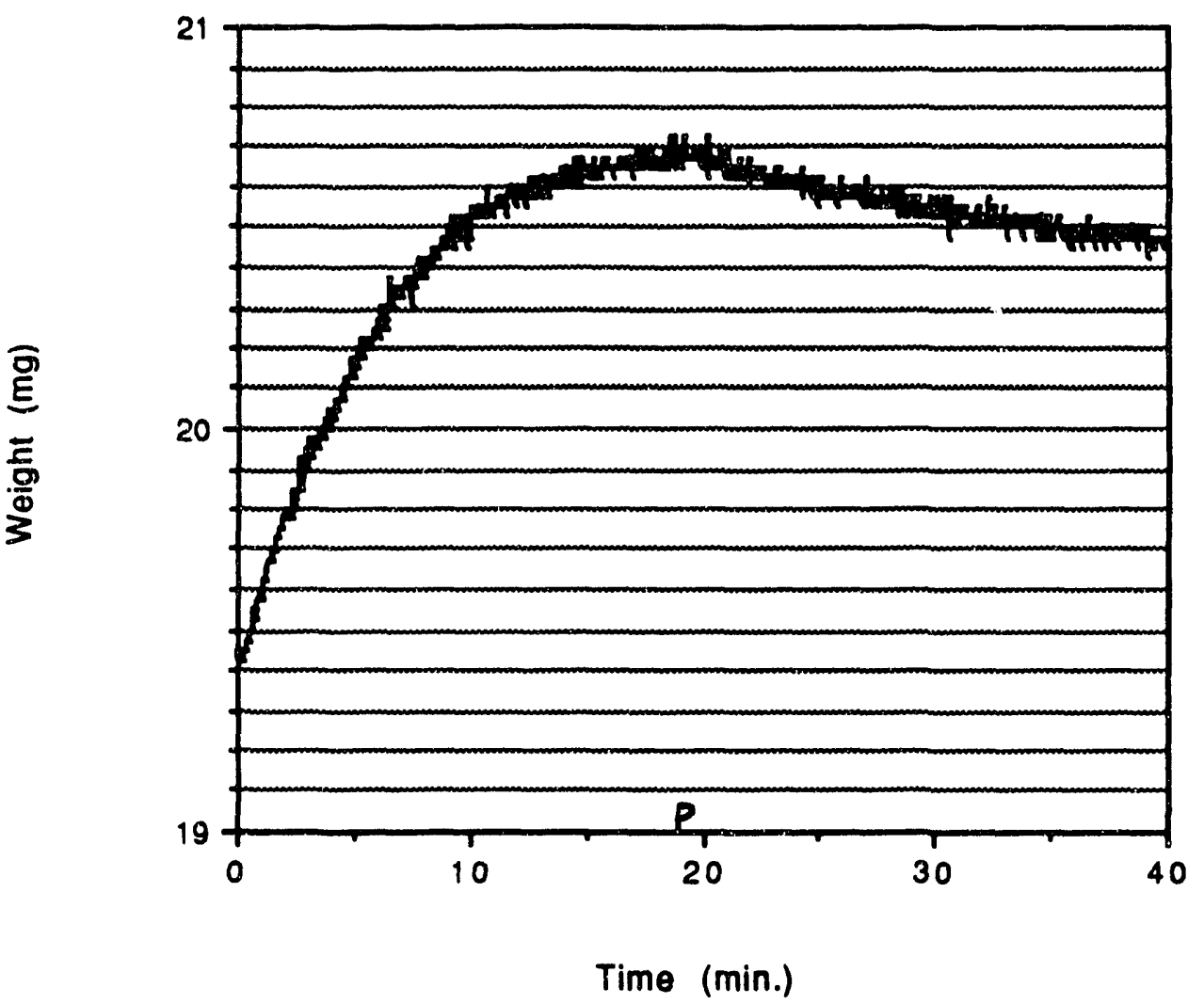

Figure 11. Weight of sample V450 during first reaction with $5 \% \mathrm{TiCl} 4-\mathrm{N}_{2}$ at $450^{\circ} \mathrm{C}$ and subsequent purge with $\mathrm{N} 2$ at the same temperature. Point $\mathrm{P}$ indicates the termination of $\mathrm{TiCl}_{4}$ flow and beginning of purge period. 


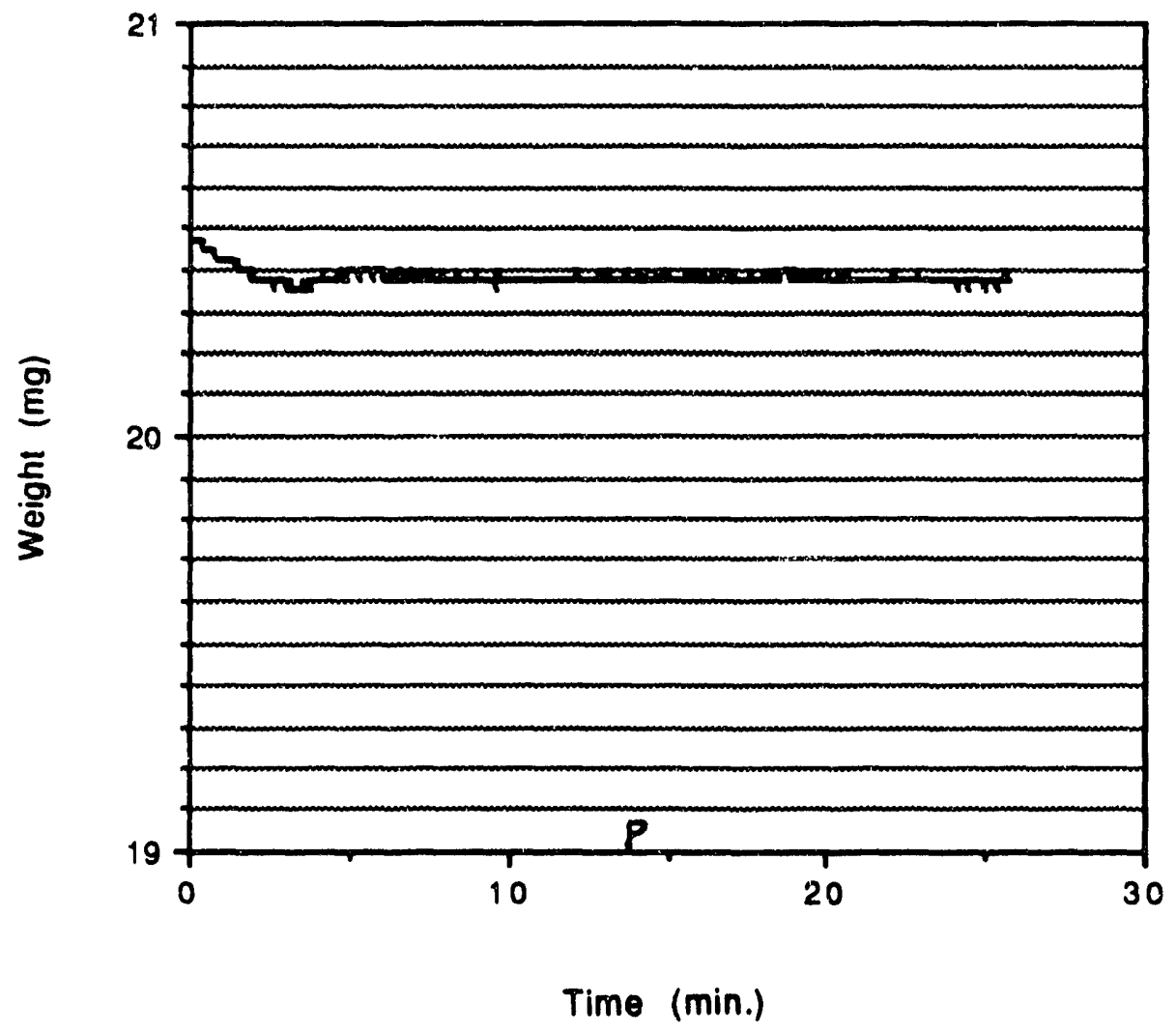

6

c

Figure 12. Weight of sample V450 prereacted as specified in Figure 1 , during hydrolysis at $450^{\circ} \mathrm{C}$. Point $P$ signifies the termination of $\mathrm{H}_{2} \mathrm{O}$ flow and beginning of purge period. 


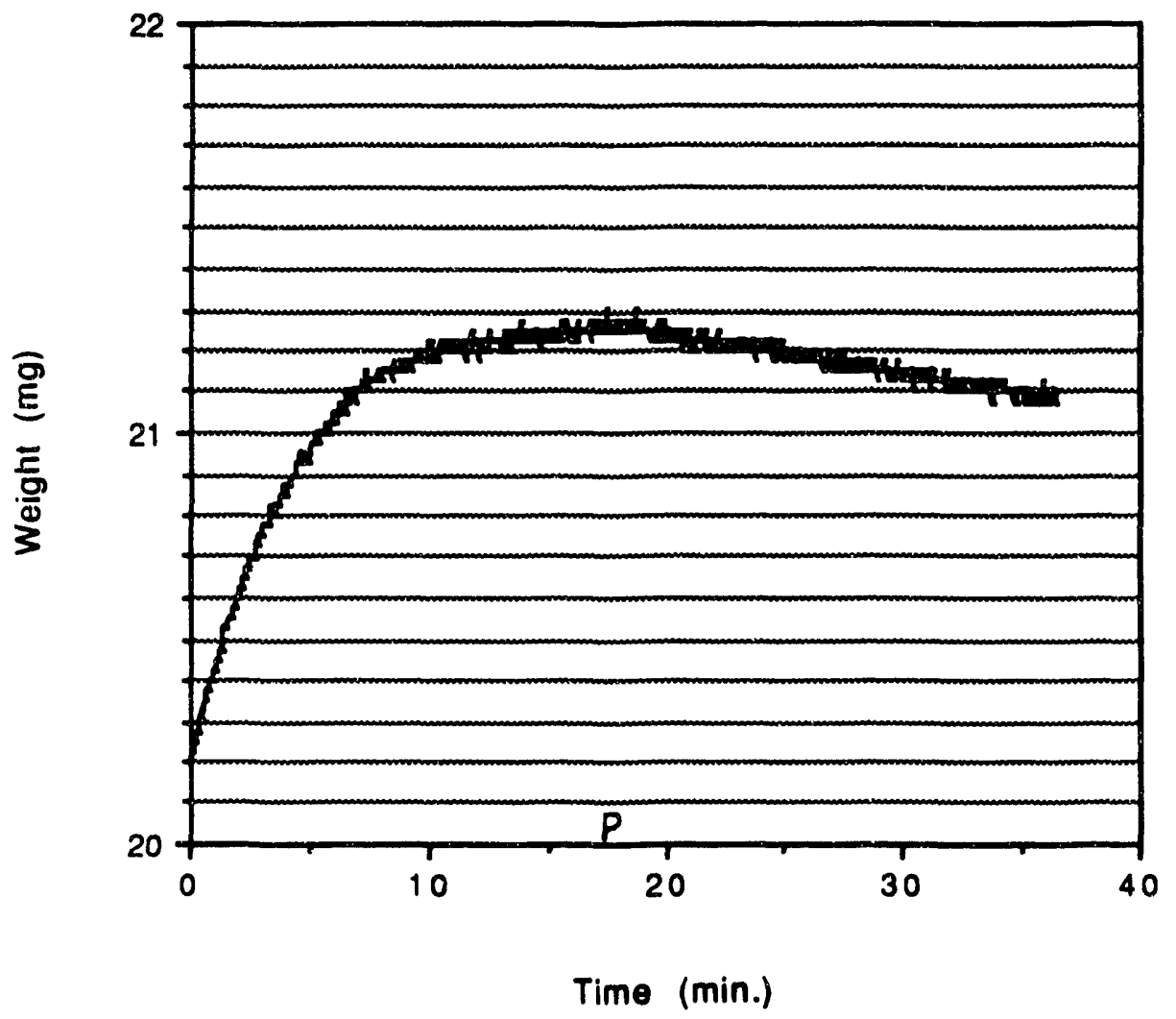

Figure 13. Second chlorination and purge of sample V450 under the same conditions as Figure 1. 


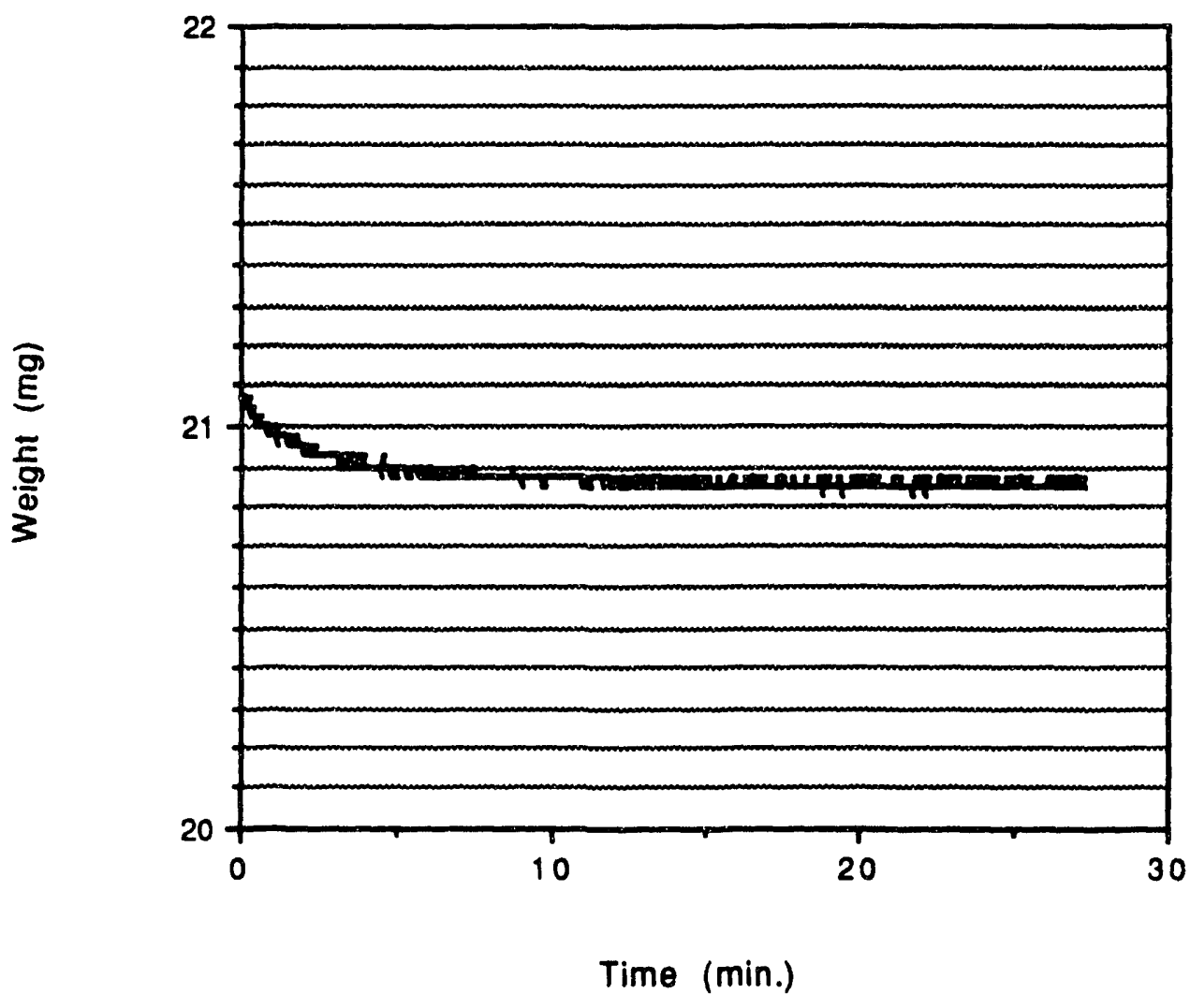

C

1

Figure 14. Second hydrolysis of V450 under the same conditions as Figure 2. 


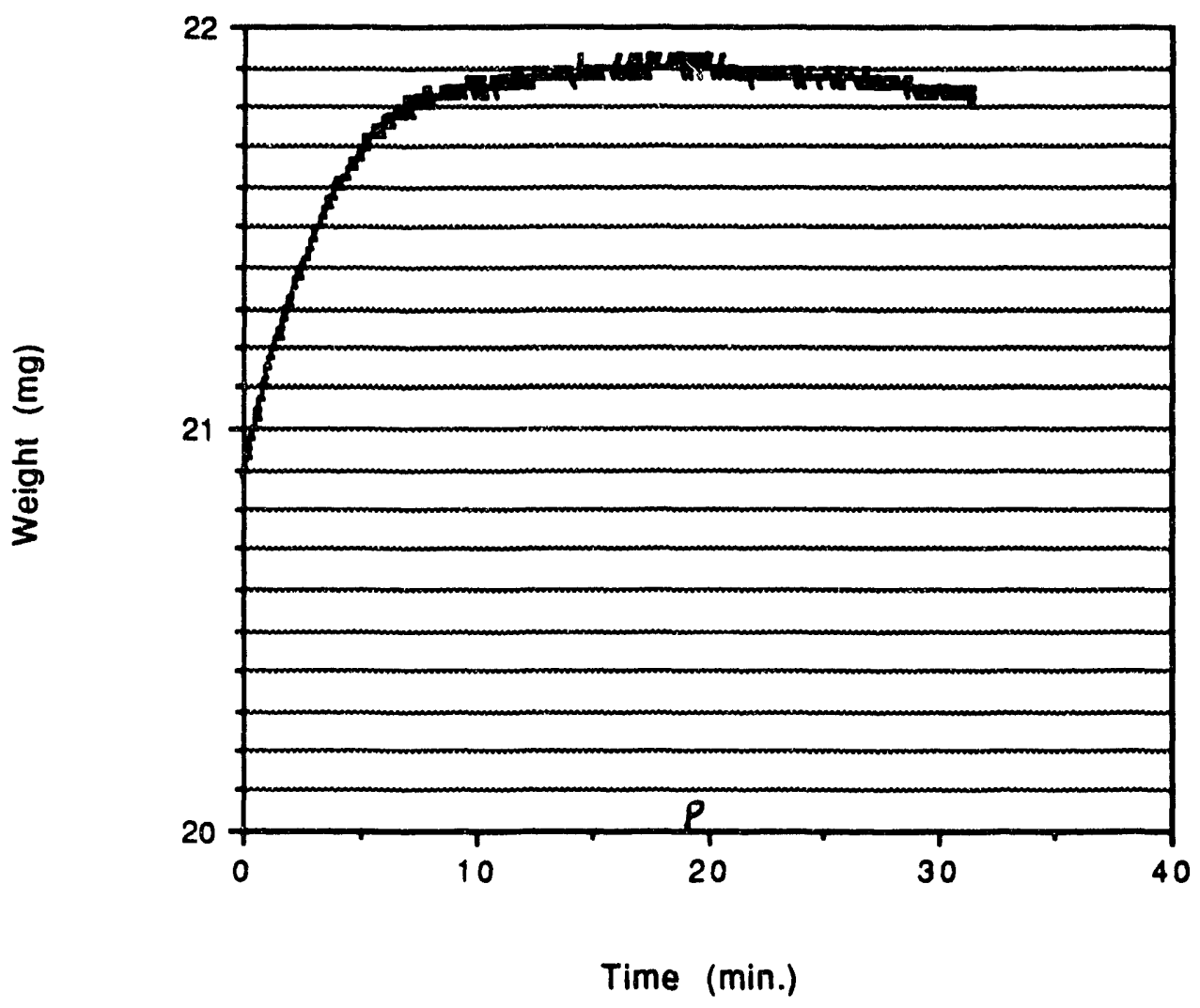

Figure 15. Third chlorination and purge of sample V450 under the same conditions as Figure 1. 


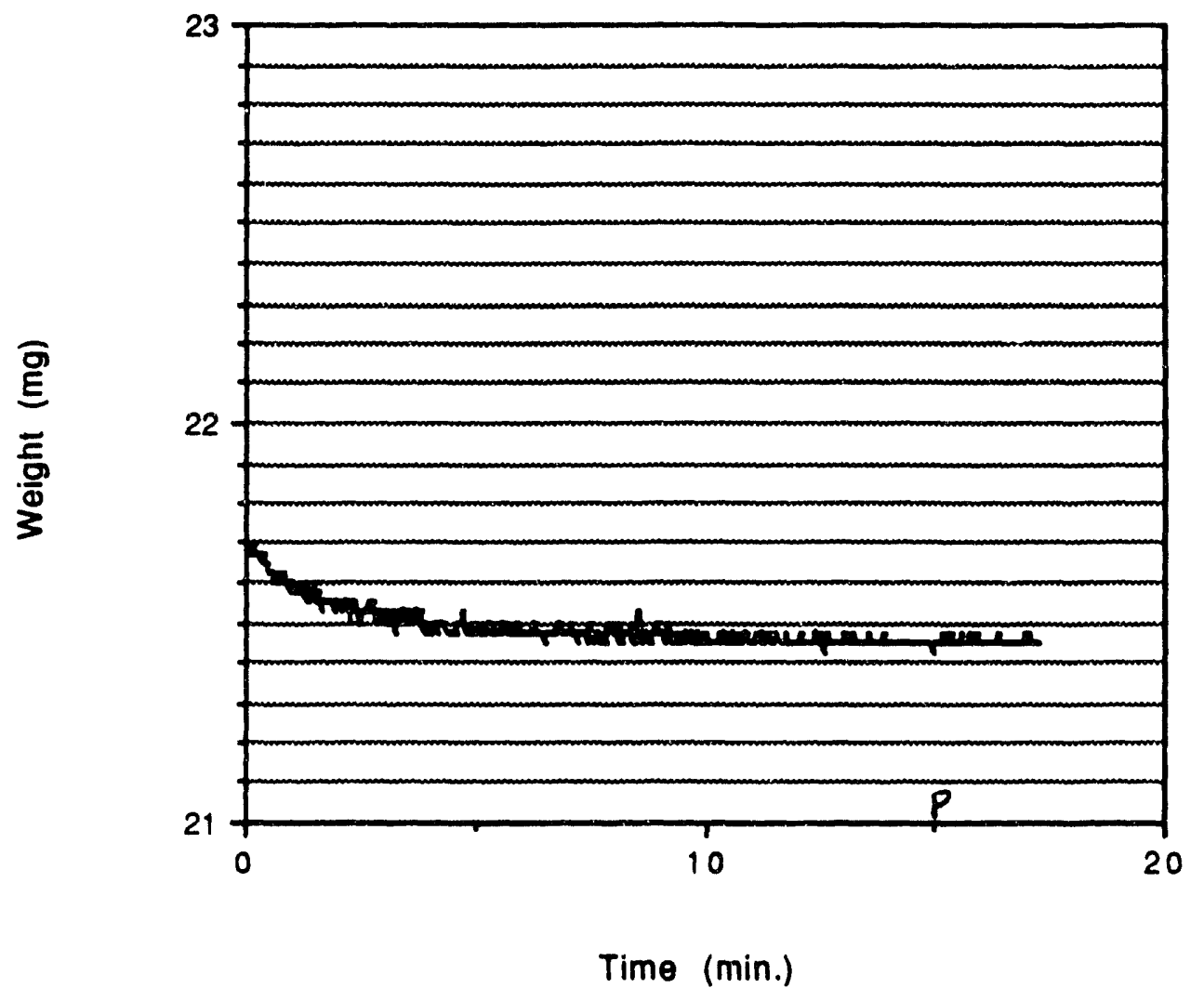

Figure 16. Third hydrolysis of V450 under the same conditions as Figure 2. 


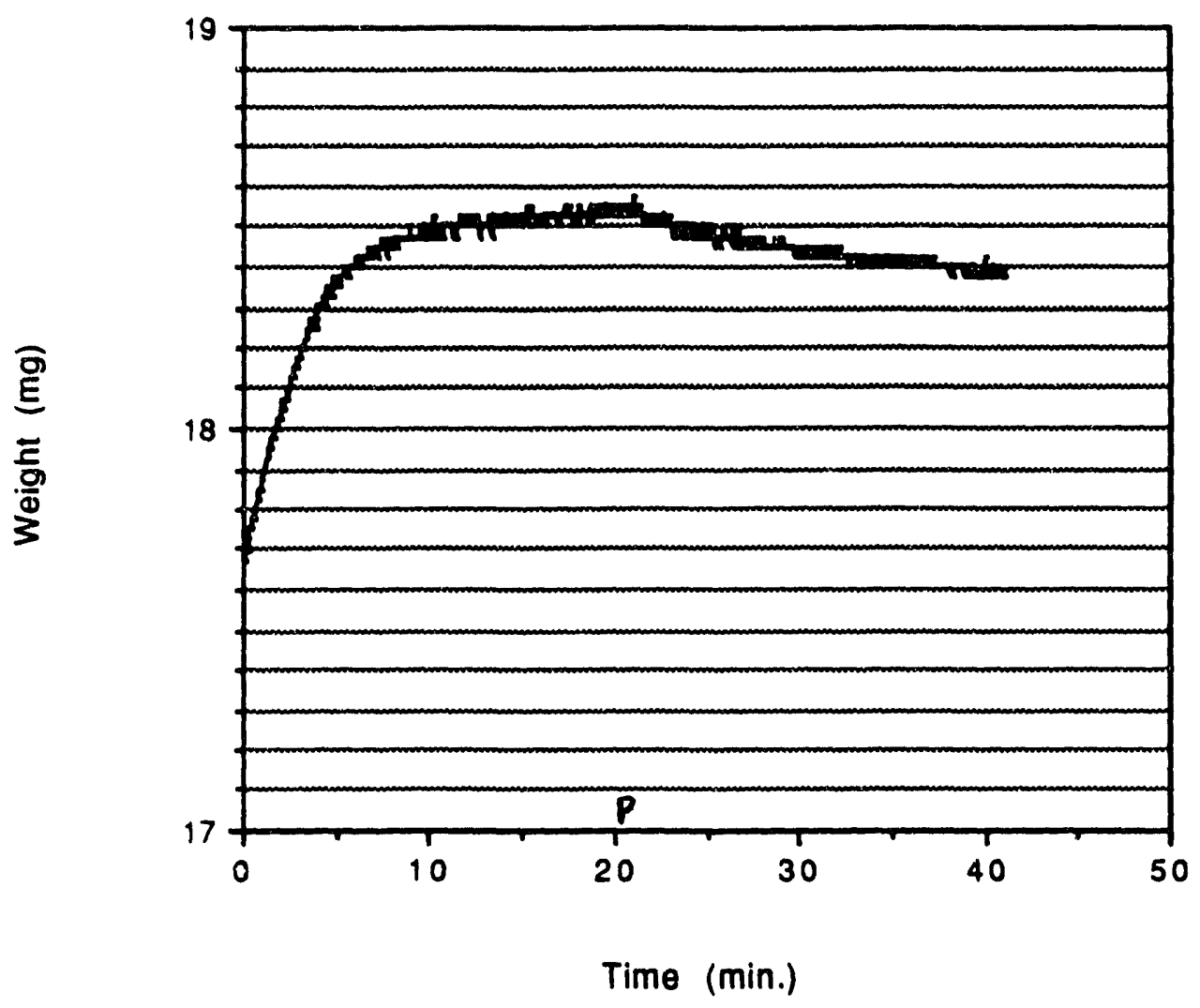

Figure 17. Weight of sample V600 during first reaction with $5 \% \mathrm{TiCl} 4-\mathrm{N} 2$ at $450^{\circ} \mathrm{C}$ and subsequent purge with $\mathrm{N}_{2}$ at the same temperature. Point $\mathrm{P}$ indicates the termination of $\mathrm{TiCl}_{4}$ flow and beginning of purge period. 


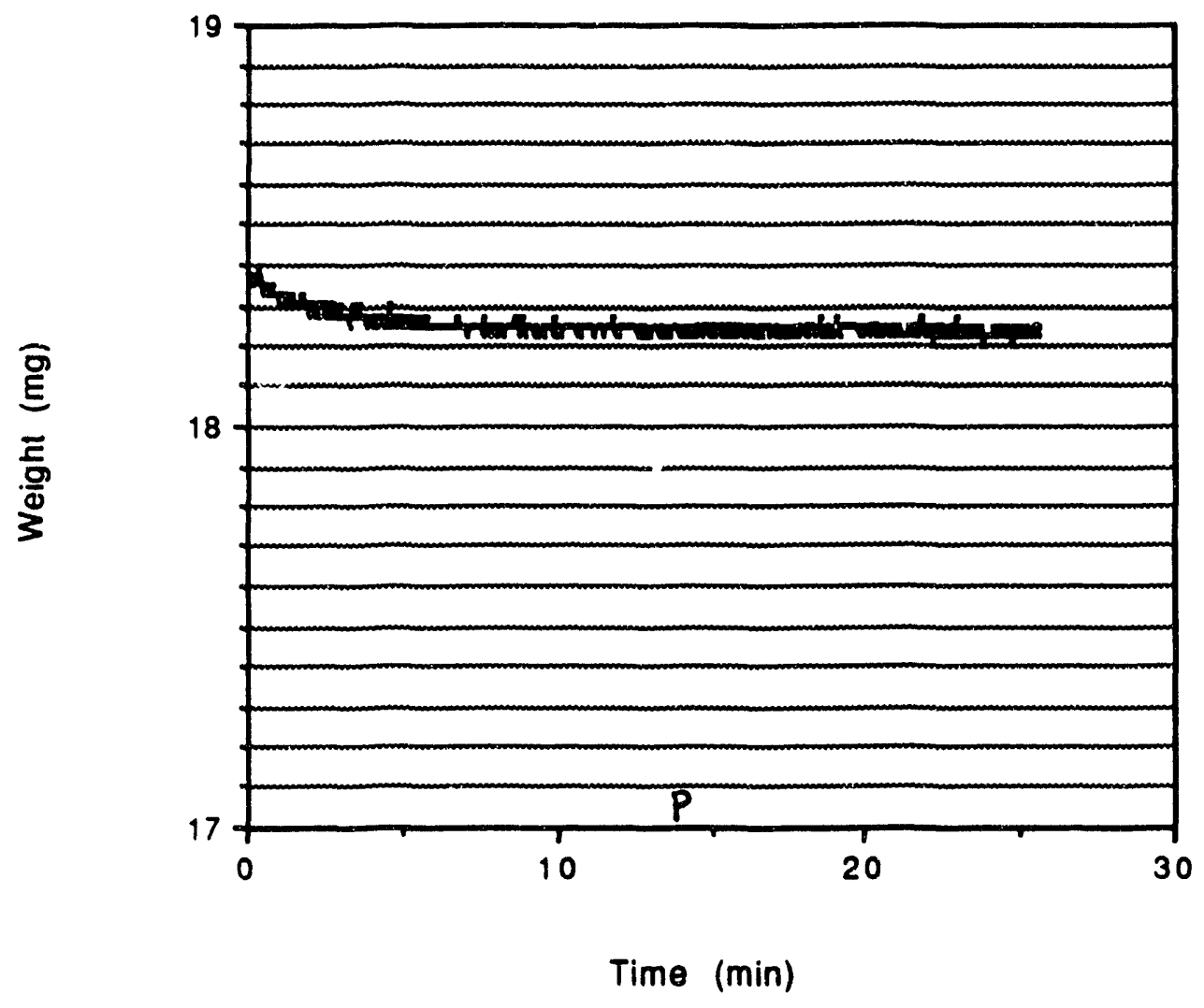

Figure 18. Weight of sample V600 prereacted as specified in Figure 7 , during hydrolysis at $450^{\circ} \mathrm{C}$. Point $P$ signifies the termination of $\mathrm{H}_{2} \mathrm{O}$ flow and beginning of purge period. 


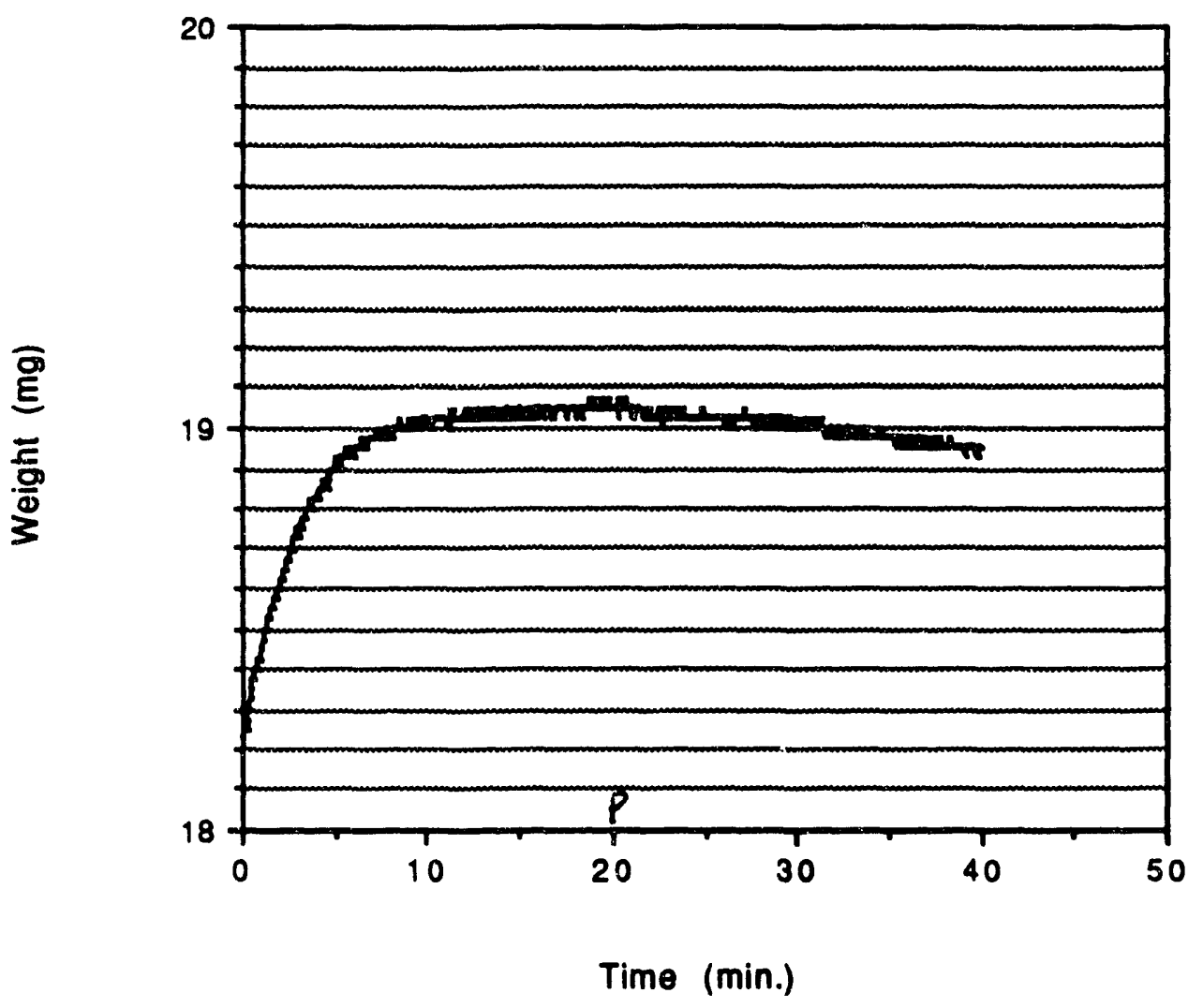

Figure 19. Second chlorination and purge of sample V600 under the same conditions as Figure 7. 


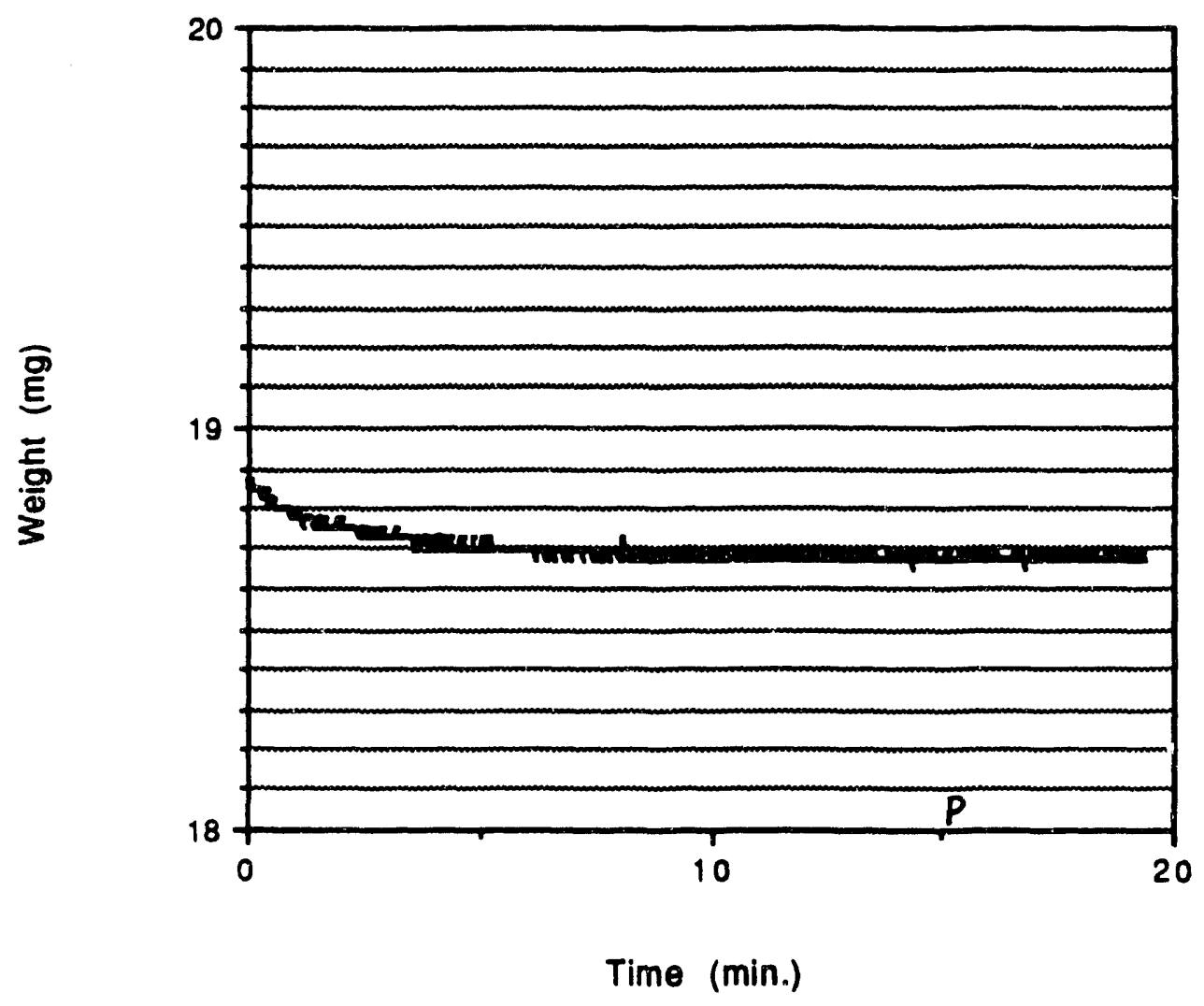

Figure 20. Second hydrolysis of V450 under the same conditions as Figure 8. 


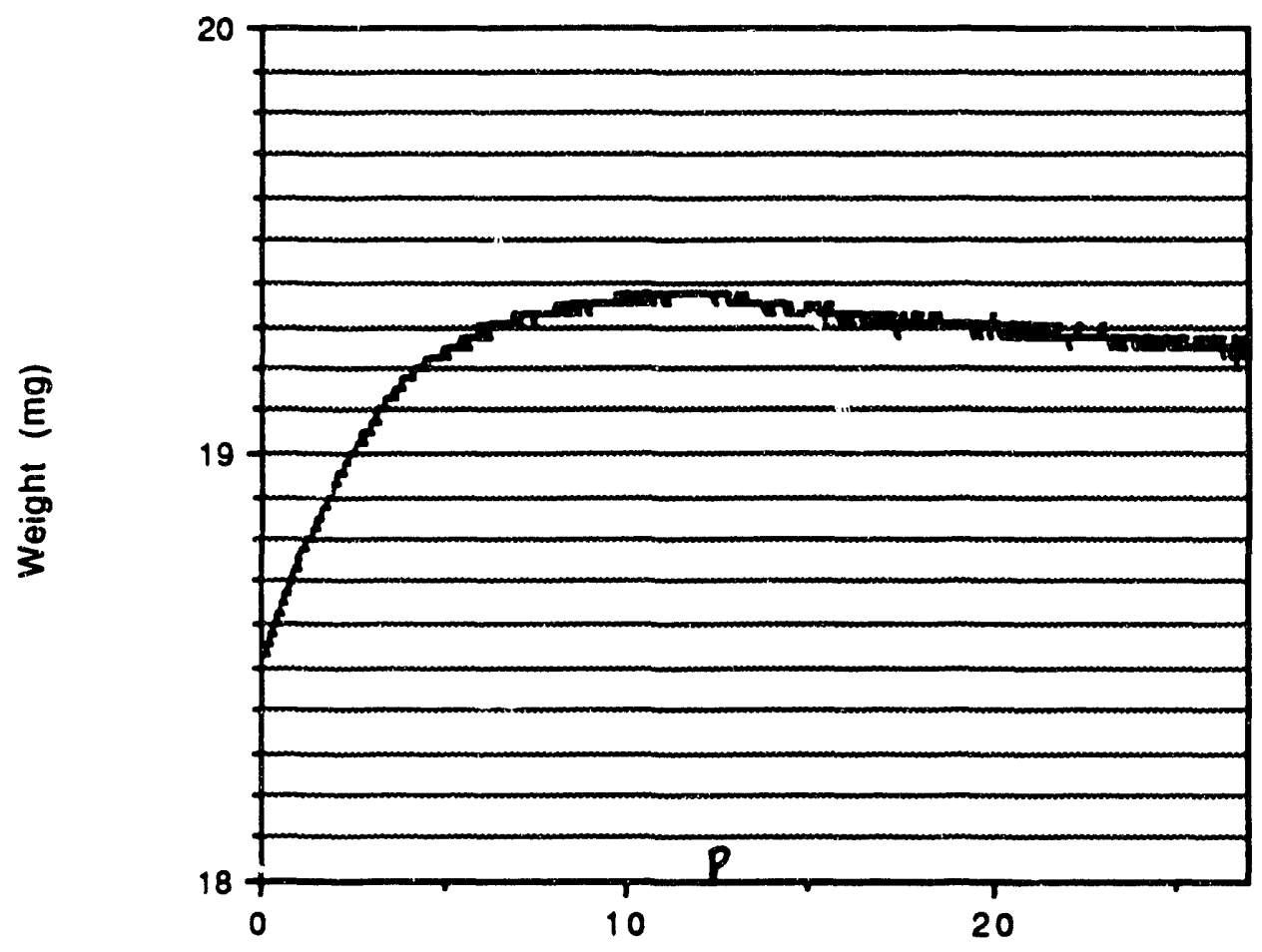

Time (mim.)

Figure 21. Weight of sample V600 during first reaction with $5 \% \mathrm{TiCl} 4-\mathrm{N}_{2}$ at $600^{\circ} \mathrm{C}$ and subsequent purge with $\mathrm{N}_{2}$ at the same temperature. Point $\mathrm{P}$ indicates the termination of $\mathrm{TiCl}_{4}$ flow and beginning of purge period. 


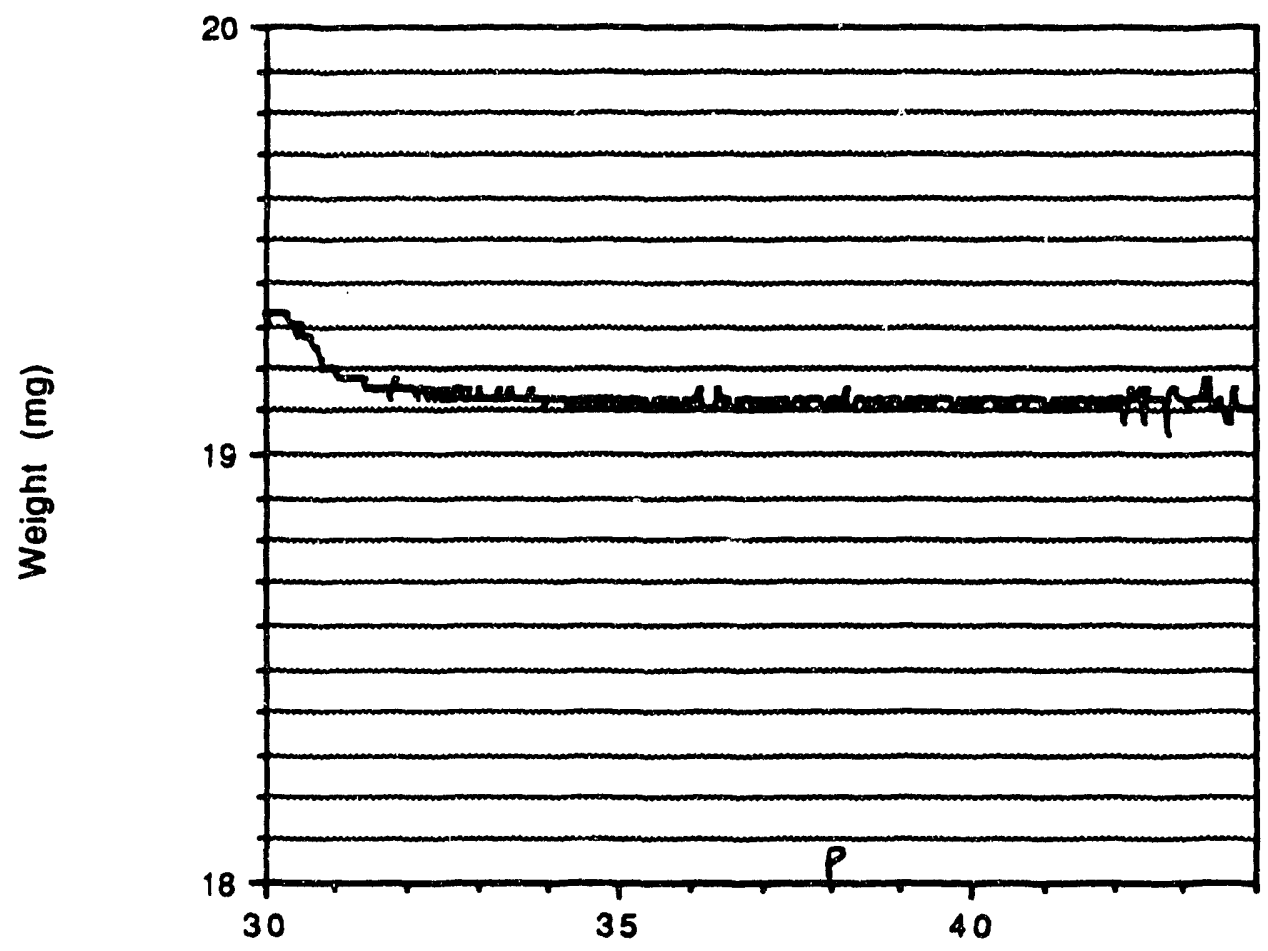

C

Time (mim.)

Figure 22. Weight of sample V600 prereacted as specified in Figure 11 , during hydrolysis at $600^{\circ} \mathrm{C}$. Point $P$ signifies the termination of $\mathrm{H}_{2} \mathrm{O}$ flow and beginning of purge period. 


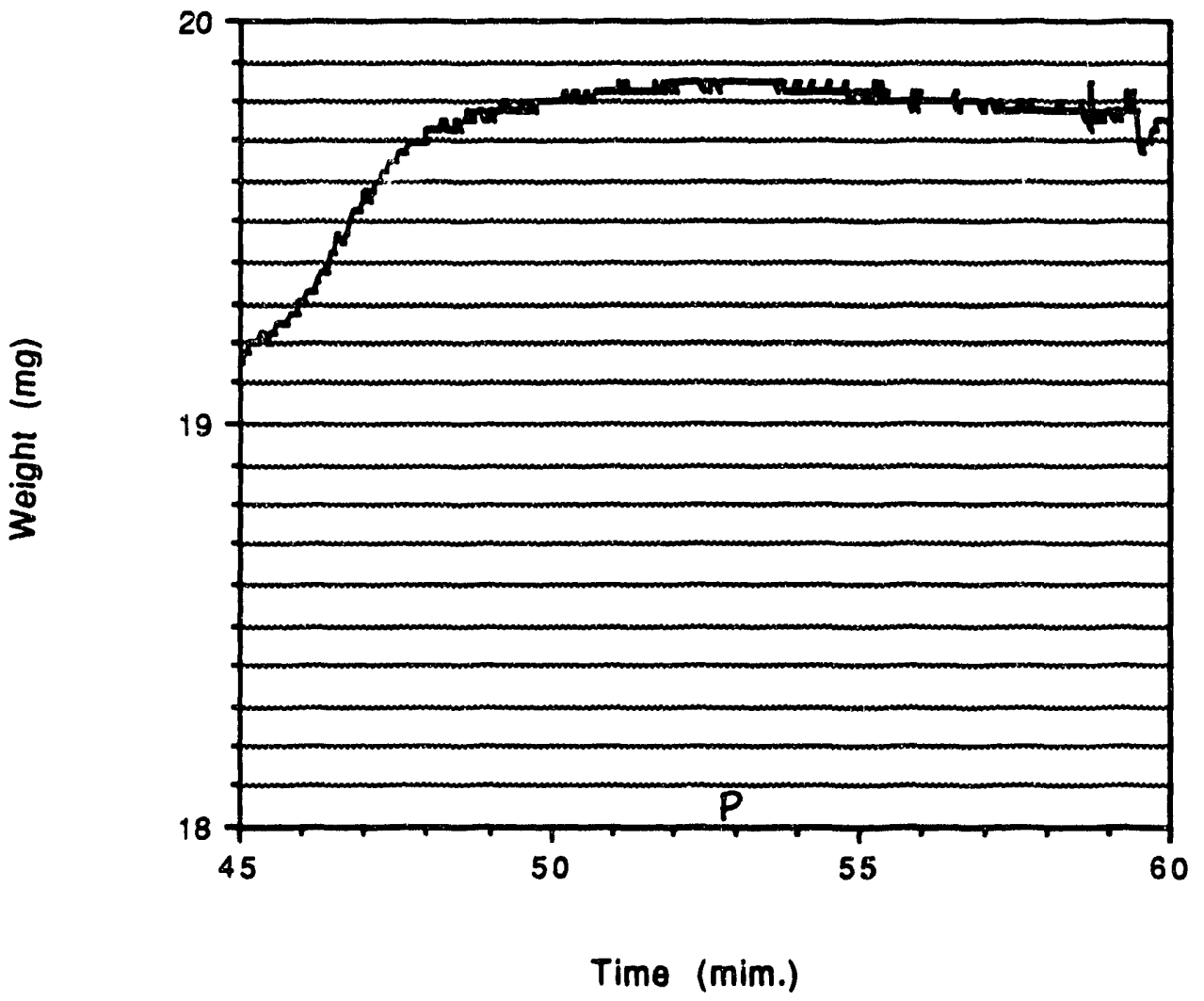

Figure 23. Second chlorination and purge of sample V600 under the same conditions as Figure 11. 


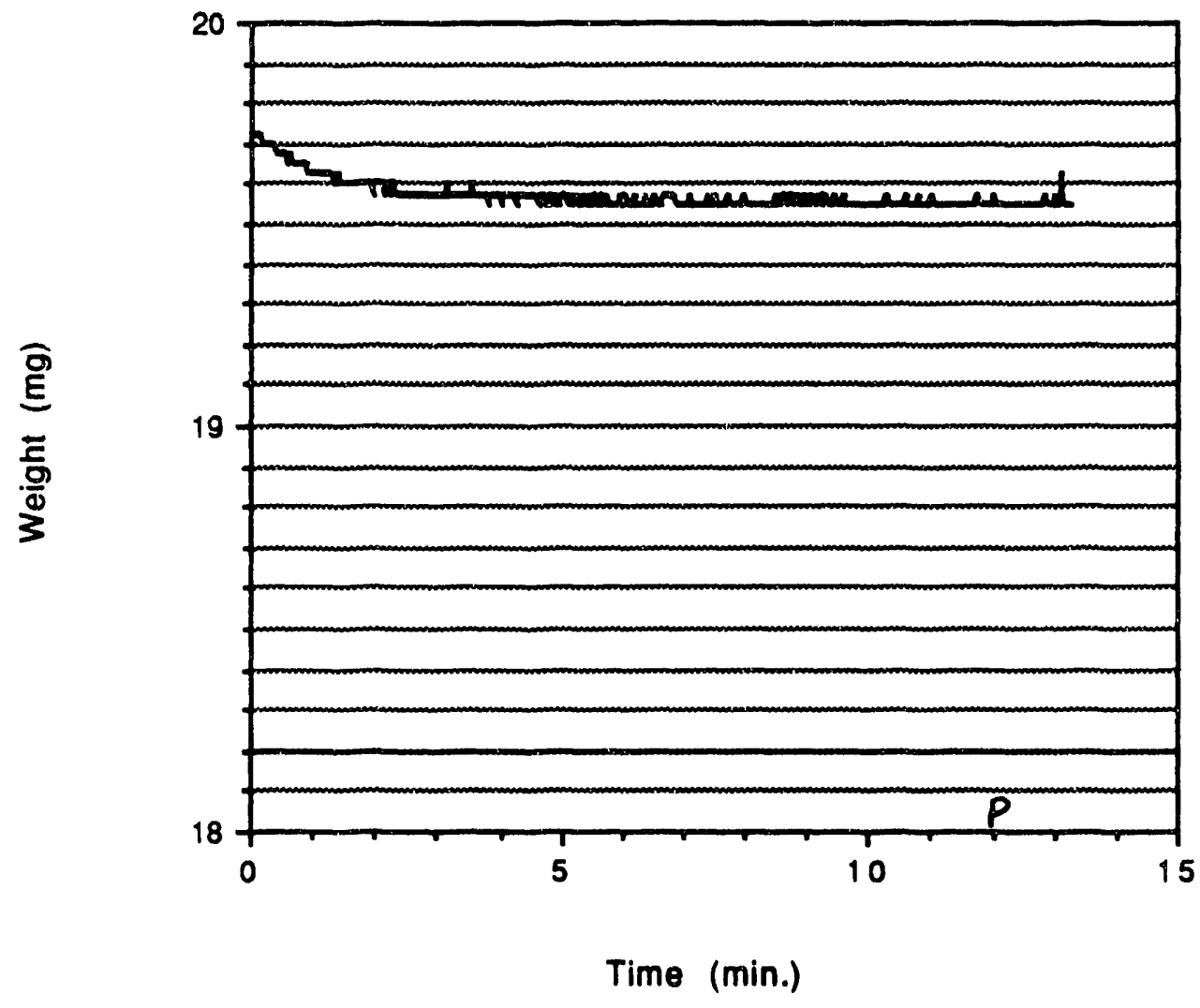

Figure 24. Srcond hydrolysis of V600 under the same conditions as Figure 12. 


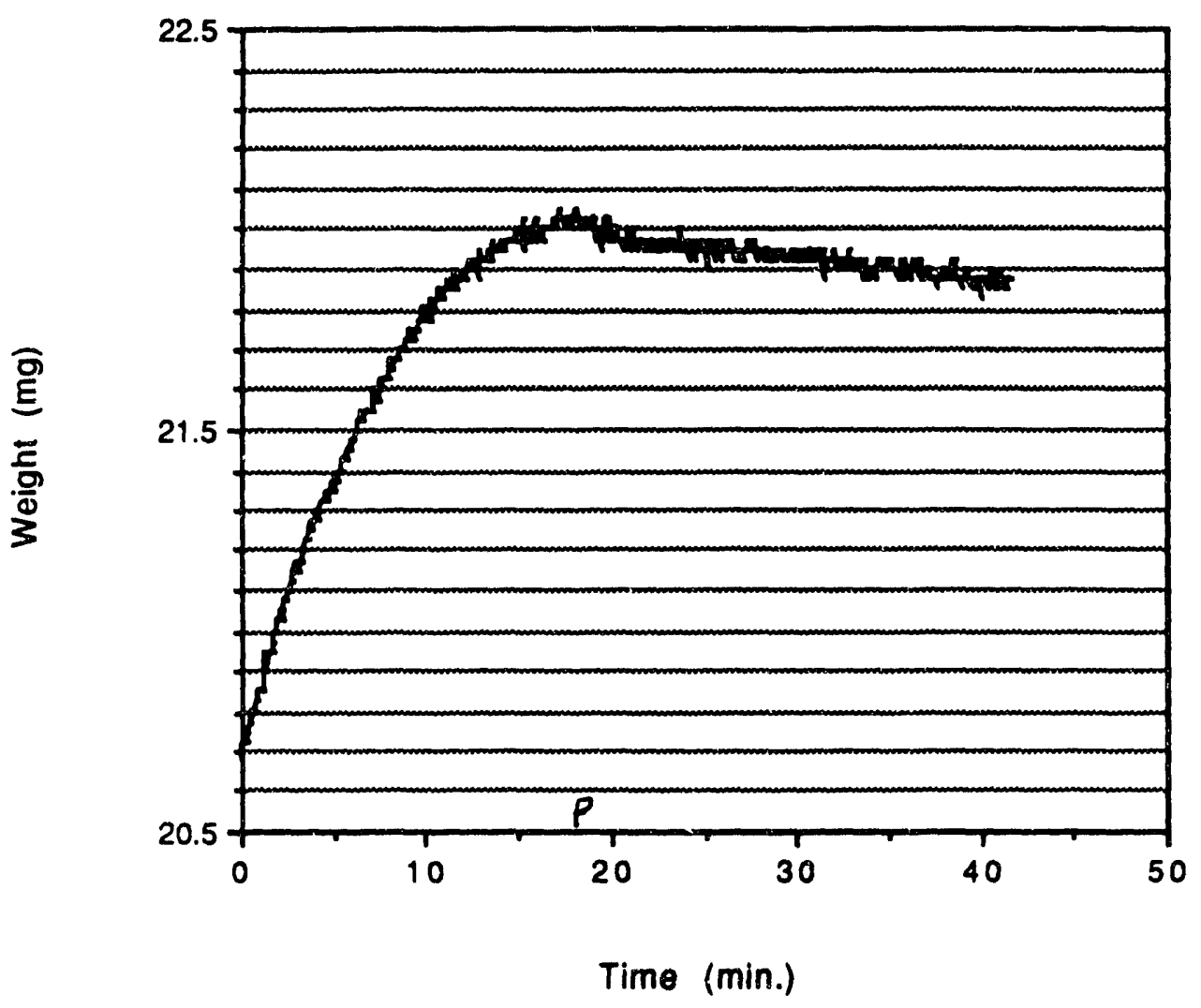

Figure 25. Weight of sample V600 during first reaction with $5 \% \mathrm{TiCl} 4-\mathrm{N}_{2}$ at $200^{\circ} \mathrm{C}$ and subsequent purge with $\mathrm{N}_{2}$ at the same temperature. Point $\mathrm{P}$ indicates the termination of $\mathrm{TiCl} 4$ flow and beginning of purge period. 


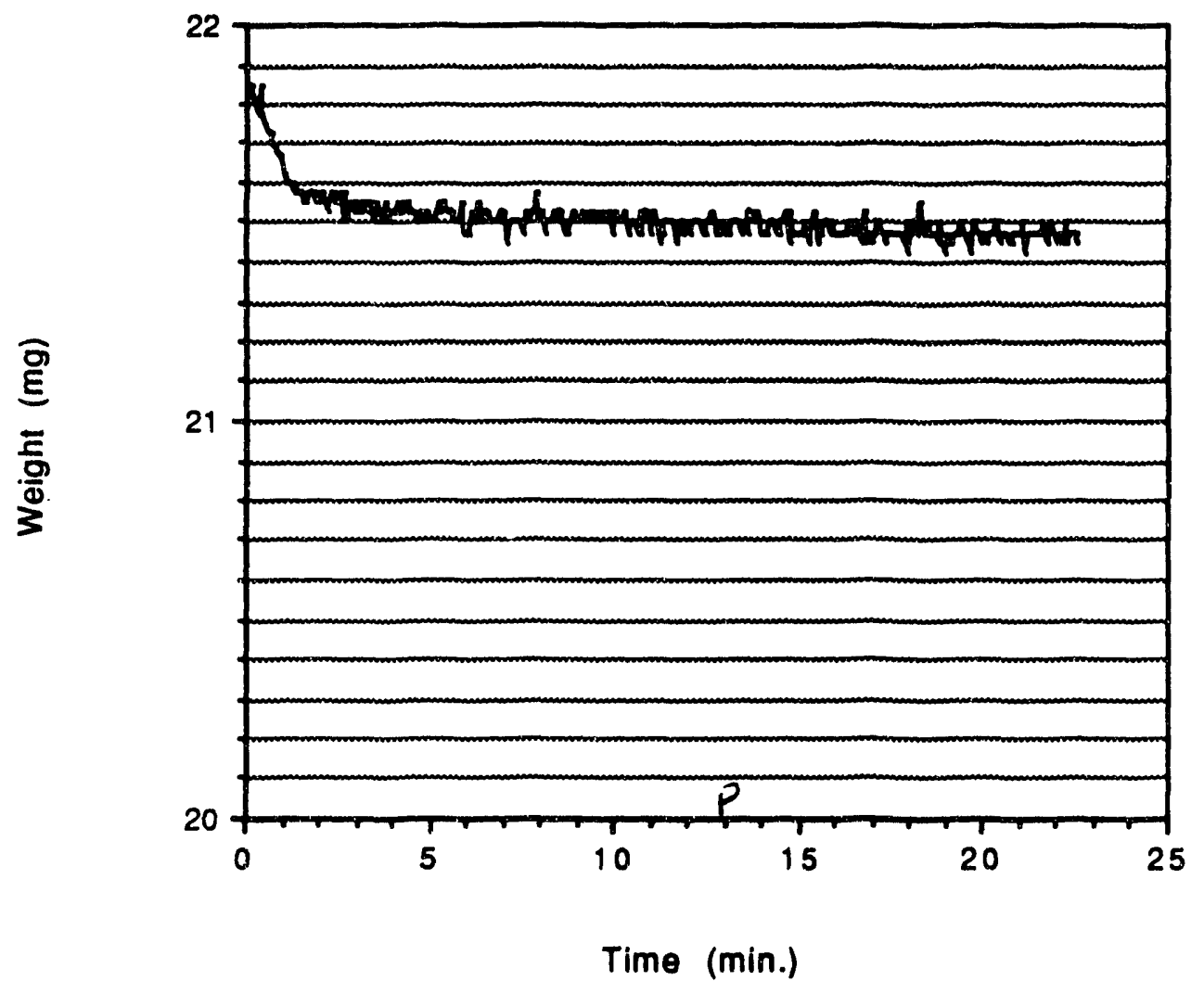

Figure 26. Weight of sample V600 prereacted as specified in Figure 15, during hydrolysis at $200^{\circ} \mathrm{C}$. Point $\mathrm{P}$ signifies the termination of $\mathrm{H}_{2} \mathrm{O}$ flow and beginning of purge period. 


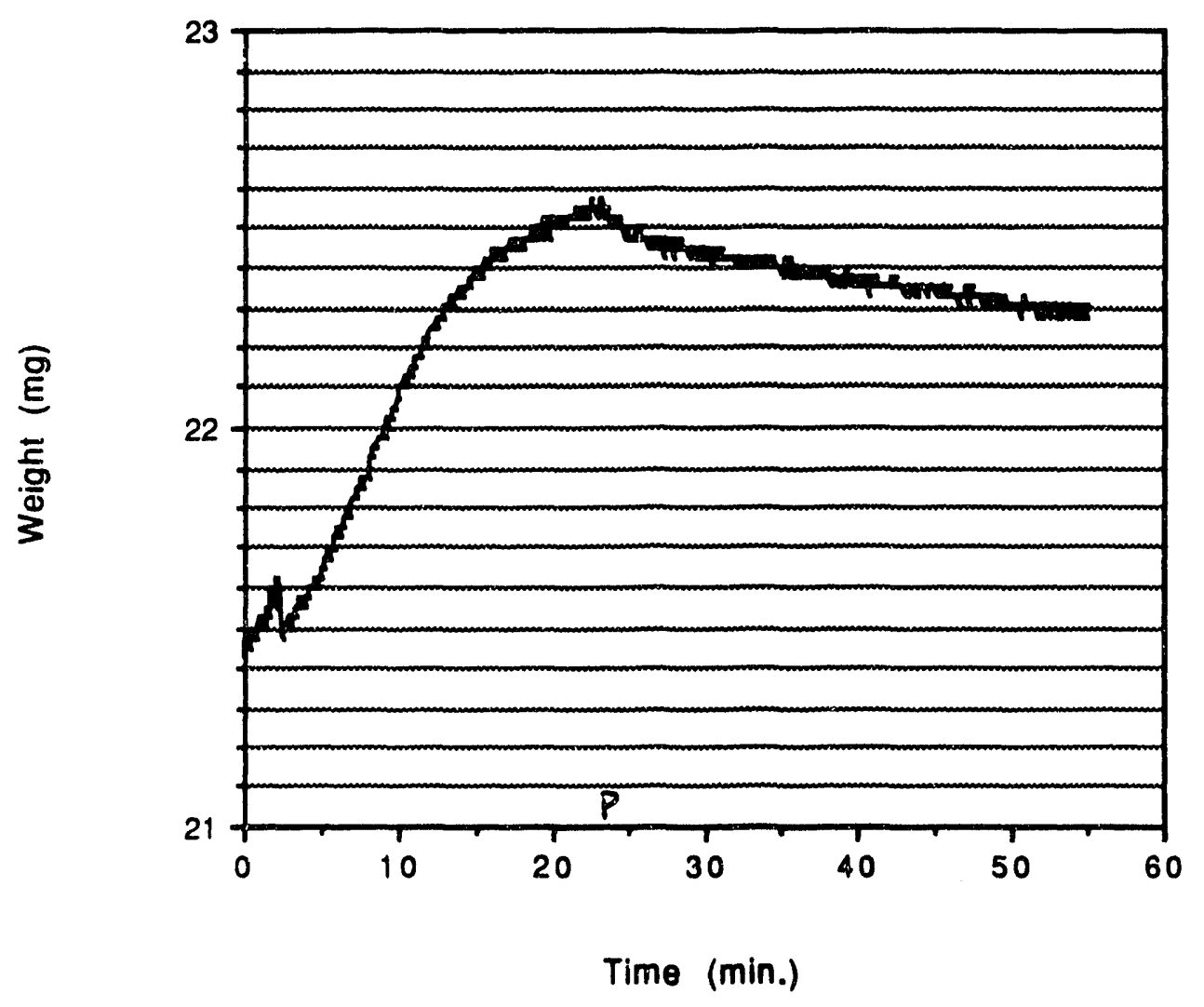

Figure 27. Second chlorination and purge of sample V600 under the same conditions as Figure 15. 


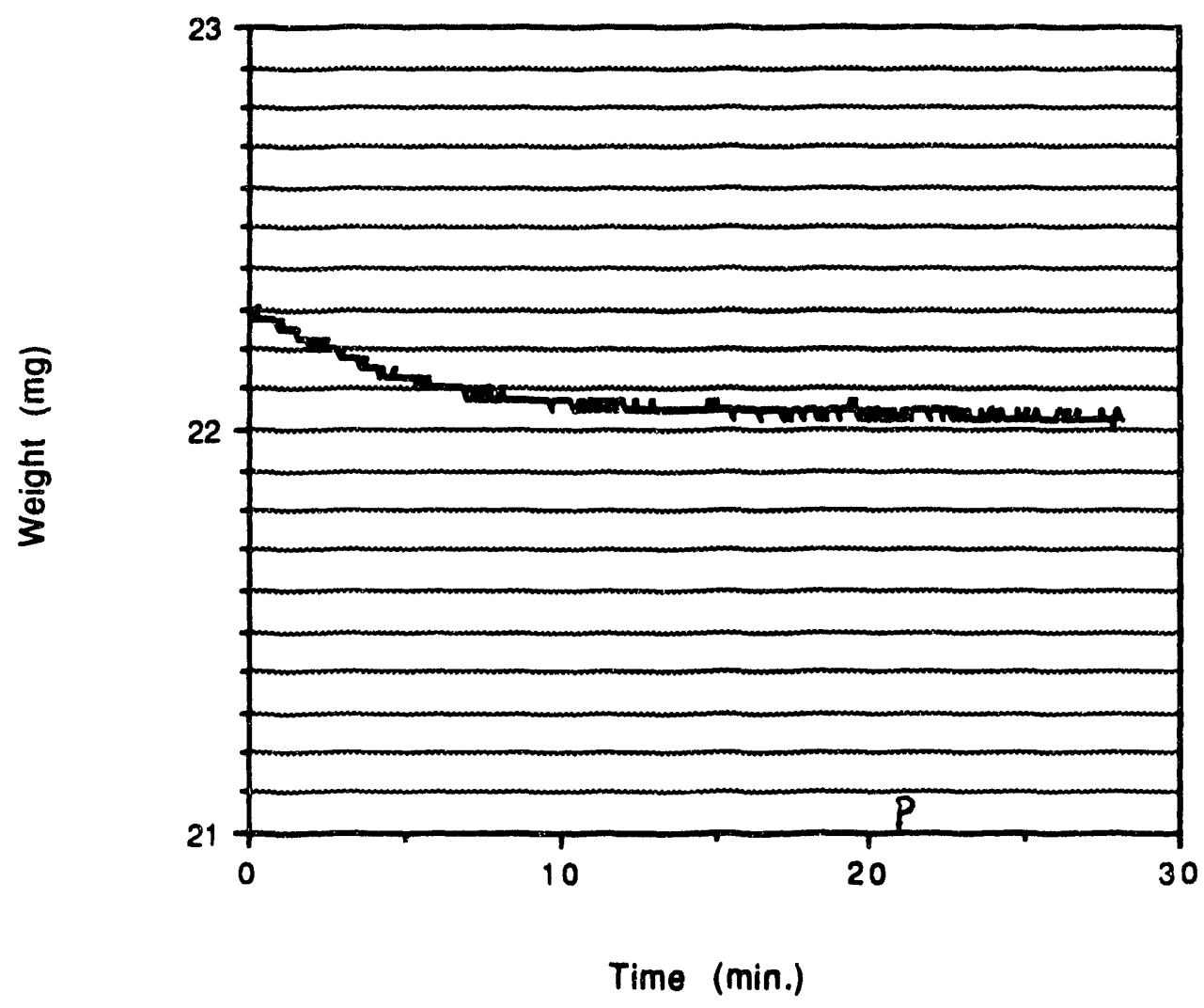

-

c

Figure 28. Second hydrolysis of V600 under the same conditions as Figure 16.

c 


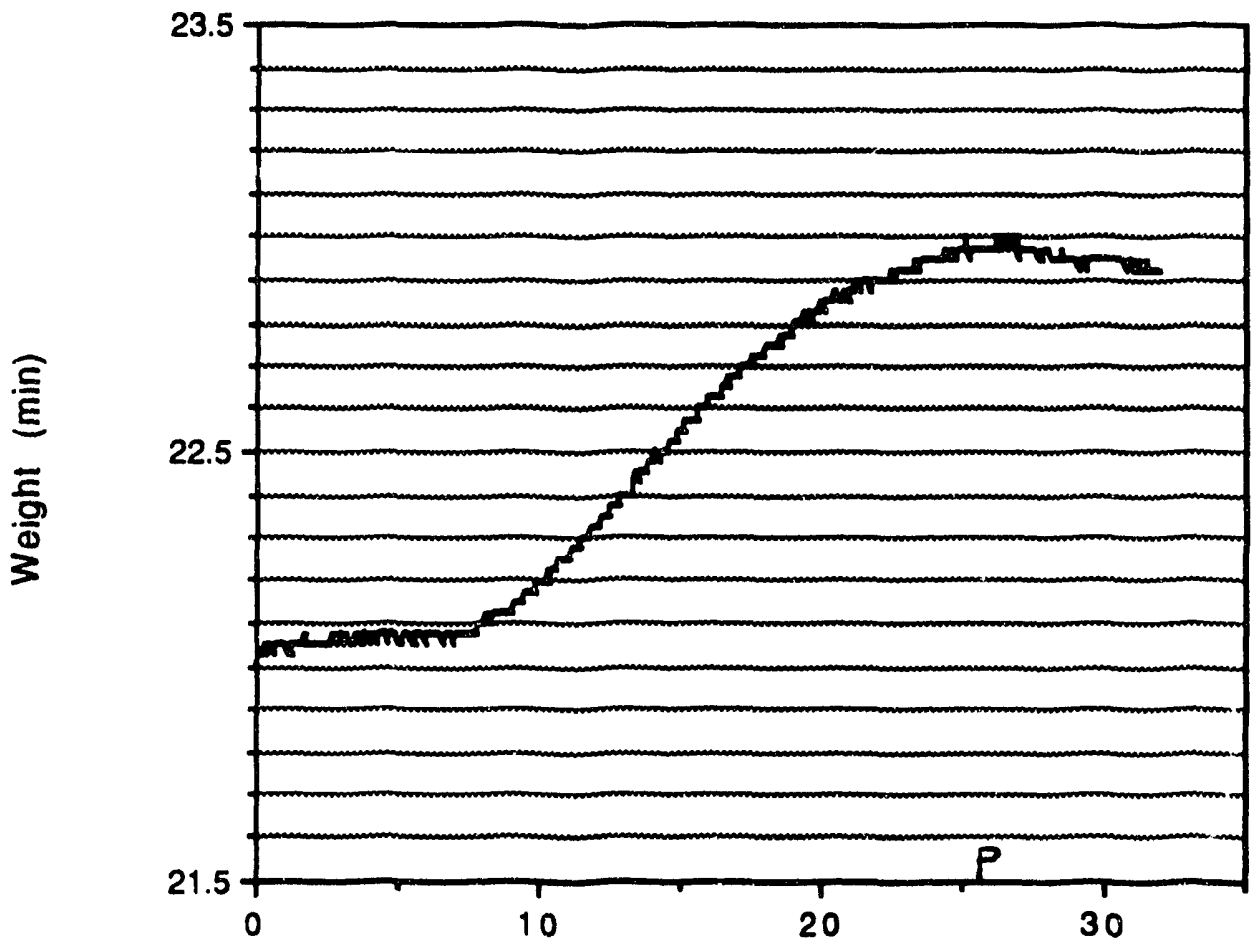

Time (min.)

Figure 29. Third chlorination and purge of sample V600 under the same conditions as Figure 15. 


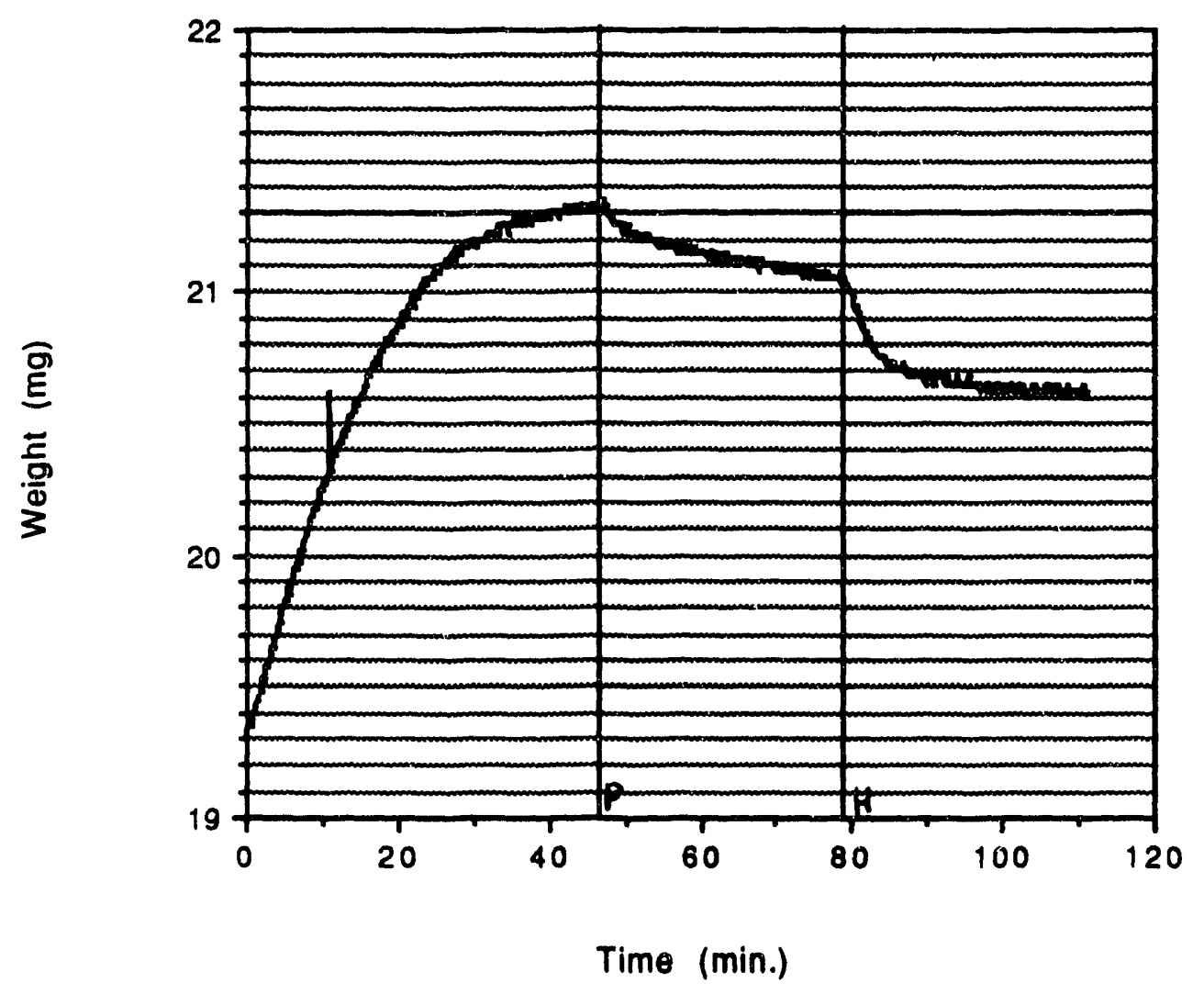

Figure 30. Weight of sample V200 during the reaction with $5 \% \mathrm{TiCl}_{4}-\mathrm{N}_{2}$ at $200^{\circ} \mathrm{C}$, subsequent purge with $\mathrm{N} 2$, and hydrolysis at the same temperature. Point $P$ indicates the termination of $\mathrm{TiCl}_{4}$ flow and beginning of purge period. Point $\mathrm{H}$ signifies the start of hydrolysis. 


\section{Chapter 5}

CONCLUSIONS

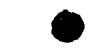

-

$\bullet$

$\bullet$

-

-

○ 


\section{CONCLUSIONS}

1. Silica layers supported on porous $V y c o r$ tubes can be prepared by chemical vapor deposition (CVD) using the reactants $\mathrm{SiCl}_{4}$ and $\mathrm{H}_{2} \mathrm{O}$ at $600-750^{\circ} \mathrm{C}$. The deposition can be carried out in one-sided geometry or in the opposing reactants geometry. In the one-sided geometry both reactants are passed through the bore of the support tube or around the outer surface of the tube. In the opposing reactants geometry one reactant is passed through the bore and the other around the outside surface of the tube. The composite membranes prepared in either of the two geometries are highly permselective to hydrogen with $\mathrm{H}_{2}: \mathrm{N}_{2}$ separation ratios in the range 500-5000 depending on the deposition conditions. Between the two deposition geometries, the one-sided deposition gave thinner $\mathrm{SiO}_{2}$ layers possessing higher hydrogen permeance but somewhat lower selectivity.

2. Opposing reactants deposition can also be used to prepare supported $\mathrm{TiO}_{2}$ and $\mathrm{Al}_{2} \mathrm{O}_{3}$ layers using the reaction mixtures $\mathrm{TiCl}_{4}-\mathrm{H}_{2} \mathrm{O}$ and $\mathrm{AlCl}_{3}-\mathrm{H}_{2} \mathrm{O}$ respectively. The $\mathrm{TiO}_{2}$ and $\mathrm{Al}_{2} \mathrm{O}_{3}$ membranes had hydrogen permeance and selectivity below those of the $\mathrm{SiO}_{2}$ membranes prepared by opposing reactants deposition. $\mathrm{TiO}_{2}$ and $\mathrm{Al}_{2} \mathrm{O}_{3}$ membranes could not be prepared by one-sided deposition.

3. The $\mathrm{SiO}_{2}$ membranes prepared by one-sided deposition had hydrogen permeance at $500^{\circ} \mathrm{C}$ of about $0.3 \mathrm{~cm}^{3} / \mathrm{cm}^{2}$-min-atm. This permeance changed little upon extended heating in the absence of water vapor. Upon heating in an atmosphere containing substantial pressure of water vapor, however, the hydrogen permeance declined gradually and stabilized at a value approximately three times below its initial value. The permeance of other gases also underwent significant decline so that the hydrogen selectivity did not change or increased slightly. 
4. The $\mathrm{SiO}_{2}, \mathrm{TiO}_{2}$ and $\mathrm{Al}_{2} \mathrm{O}_{3}$ membranes were characterized by scanning electron microscopy (SEM), electron microprobe analysis (EMA) and transmission electron microscopy (TEM). The results of microscopy and EMA show that the membrane consists of a thin sublayer $(\sim 0.5 \mu \mathrm{m})$ of maximum deposition and a much thicker layer $(20-100 \mu \mathrm{m})$ of reduced deposition. All open pore paths within the sublayer are evidently blocked by the deposit leaving behind only some trapped porosity. This sublayer is evidently responsible for the separation selectivity of the membrane. The thicker layer of reduced deposition contains partially constricted pore paths and does not contribute much to membrane selectivity although it reduces somewhat the permeance.

5. Silica deposition takes place by a heterogeneous mechanism initiated at $-\mathrm{OH}$ groups on the pore surface of the support and propagating by reaction between gaseous $\mathrm{SiCl}_{4}$ and $-\mathrm{OH}$ groups in the deposit (silylation) and between gaseous $\mathrm{H}_{2} \mathrm{O}$ and $-\mathrm{Cl}$ groups in the deposit (hydrolysis). Condensation between - $\mathrm{OH}$ and $-\mathrm{Cl}$ groups or between two - $\mathrm{OH}$ groups round up this mechanism forming the Si-O-Si bonds of $\mathrm{SiO}_{2}$. Thermogravimetric experiments were carried out showing that the two condensation steps are much slower than the silylation and hydrolysis reactions.

6. A mathematical model was developed describing the process of membrane formation. The model is based on transient kinetics and accounts for the changes in the pore structure due to the accumulation of the $\mathrm{SiO}_{2}$ deposit. The deposit density profiles calculated by the model are in qualitative agreement with the profiles measured by EMA. 
7. Because of the high cost of Vycor tubing and the additional fabrication cost of multitube membrane modules, increasing the membrane permeance above the currently attainable values is important for commercialization of the silica membranes. Work under a new DOE-UCR grant will focus on techniques for increasing membrane permeance and on more detailed characterization of the separation layer. 

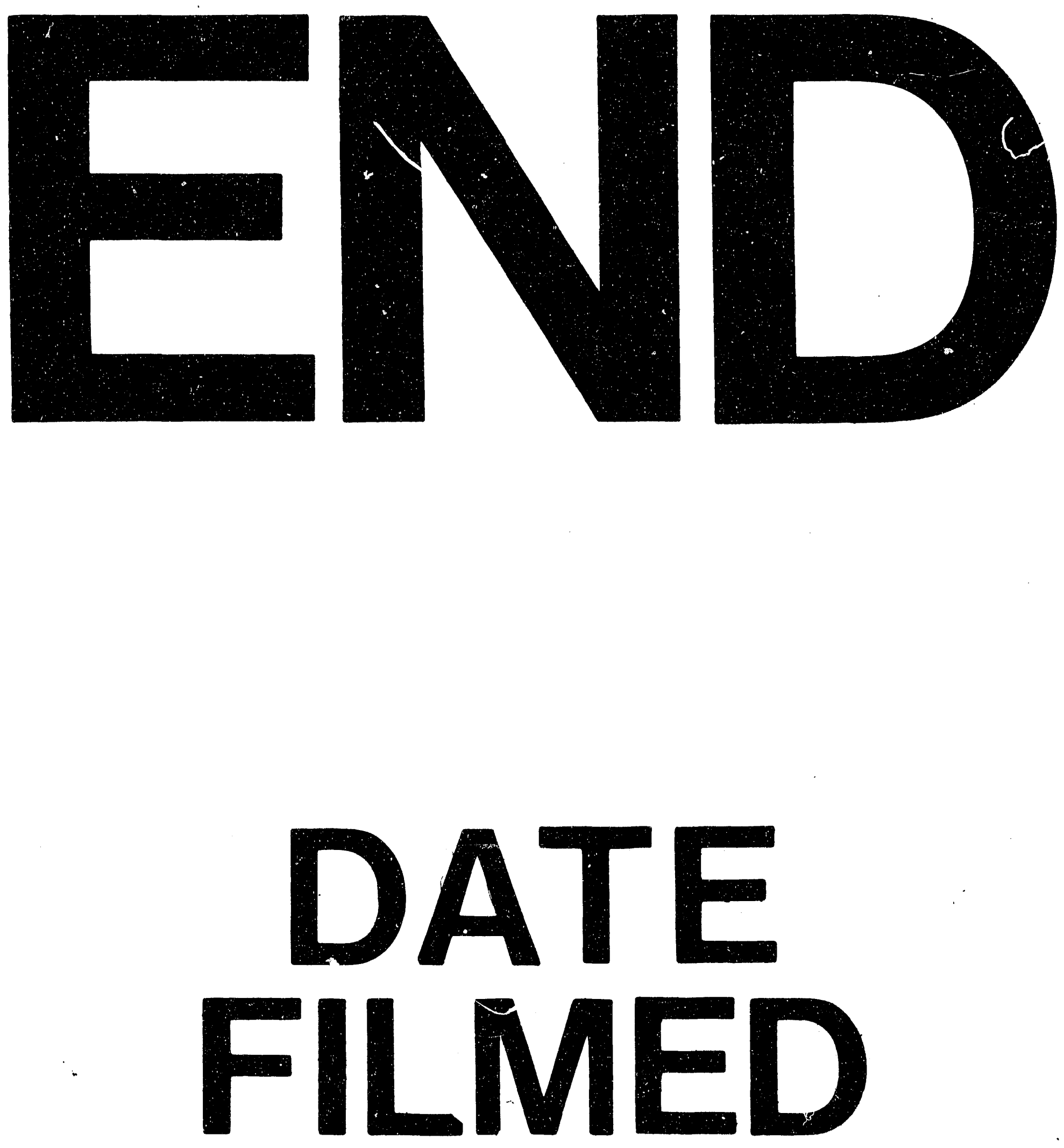

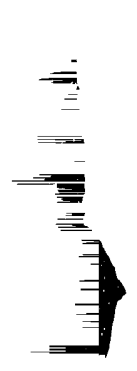

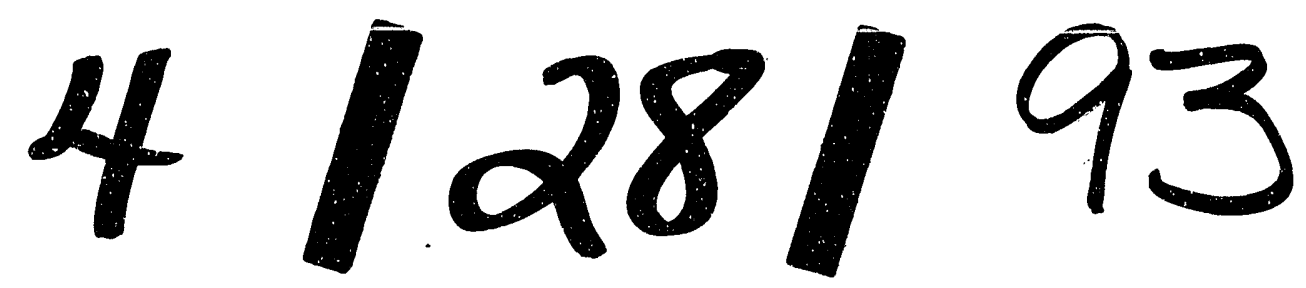


$=$

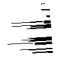

三

$\equiv$

$=$ 